\title{
Modeling the combined impact of changing climate and changing nutrient loads on the Baltic Sea environment in an ensemble of transient simulations for 1961-2099
}

\author{
H. E. M. Meier • R. Hordoir $\cdot$ H. C. Andersson • \\ C. Dieterich · K. Eilola • B. G. Gustafsson • \\ A. Höglund $\cdot$ S. Schimanke
}

Received: 20 August 2011/Accepted: 10 March 2012/Published online: 21 April 2012

(C) The Author(s) 2012. This article is published with open access at Springerlink.com

\begin{abstract}
The combined future impacts of climate change and industrial and agricultural practices in the Baltic Sea catchment on the Baltic Sea ecosystem were assessed. For this purpose 16 transient simulations for 1961-2099 using a coupled physical-biogeochemical model of the Baltic Sea were performed. Four climate scenarios were combined with four nutrient load scenarios ranging from a pessimistic business-as-usual to a more optimistic case following the Baltic Sea Action Plan (BSAP). Annual and seasonal mean changes of climate parameters and ecological quality indicators describing the environmental status of the Baltic Sea like bottom oxygen, nutrient and phytoplankton concentrations and Secchi depths were studied. Assuming present-day nutrient concentrations in the rivers, nutrient loads from land increase during the twenty first century in all investigated scenario simulations due to increased volume flows caused by increased net precipitation in the Baltic catchment area. In addition, remineralization rates increase due to increased water temperatures causing enhanced nutrient flows from the sediments. Cause-andeffect studies suggest that both processes may play an
\end{abstract}

H. E. M. Meier $(\square) \cdot$ R. Hordoir · H. C. Andersson •

C. Dieterich · A. Höglund · S. Schimanke

Department of Research and Development, Swedish

Meteorological and Hydrological Institute,

60176 Norrköping, Sweden

e-mail: markus.meier@smhi.se

K. Eilola

Department of Research and Development, Swedish

Meteorological and Hydrological Institute, Sven Källfelts gata

15, 42671 Västra Frölunda, Sweden

B. G. Gustafsson

Stockholm Resilience Centre, Baltic Nest Institute, Stockholm

University, 10691 Stockholm, Sweden important role for the biogeochemistry of eutrophicated seas in future climate partly counteracting nutrient load reduction efforts like the BSAP.

Keywords Numerical modeling $\cdot$ Baltic Sea $\cdot$ Climate change $\cdot$ Scenarios $\cdot$ Marine ecosystems $\cdot$ Eutrophication $\cdot$ Baltic Sea Action Plan

\section{Introduction}

For the Baltic Sea (Fig. 1) regional climate modeling results suggest that global warming may cause increased water temperatures and reduced sea ice cover combined (eventually) with reduced salinity due to increased wind speeds and increased river runoff (e.g. BACC author team 2008; Meier et al. 2006). The projected hydrographic changes could therefore have significant impacts on the marine ecosystem. To estimate these effects and to calculate the impact of nutrient load reductions in future climate an ensemble of model simulations for the period 1961-2099 were carried out. Ensemble simulations are necessary to estimate uncertainties of projections (e.g. Christensen and Christensen 2007; Christensen et al. 2007; Kjellström et al. 2011; Nikulin et al. 2011; Räisänen et al. 2004). Uncertainties are caused by biases of global and regional climate models and by unknown socio-economic future developments with impact on greenhouse gas emissions, nutrient loads from land and atmospheric deposition.

For the marine environment of regional seas only a few studies on uncertainties of future projections are available (e.g. Neumann 2010; Meier et al. 2011b). For instance, Neumann (2010) studied the results of two transient simulations with a coupled physical-biogeochemical model 


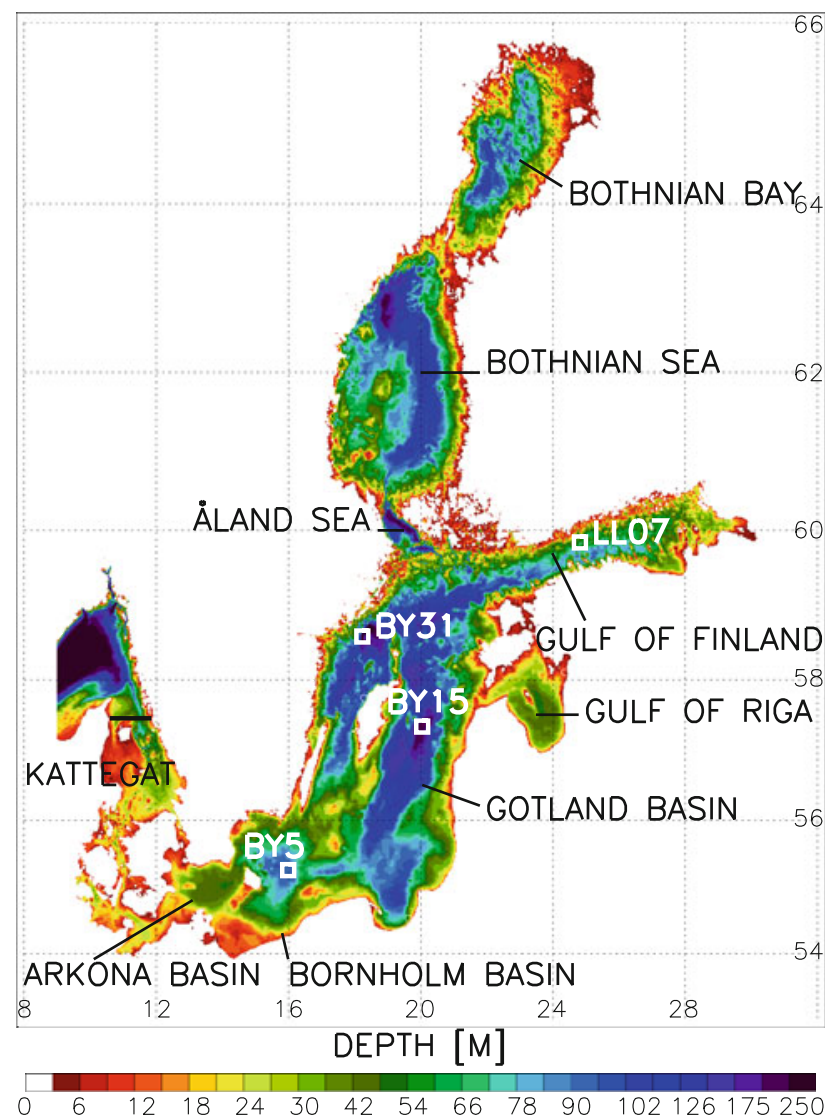

Fig. 1 Bottom topography of the Baltic Sea. The domain of the Rossby Centre Ocean model (RCO) is limited with open boundaries in the northern Kattegat (black line). In addition, the monitoring stations at Bornholm Deep (BY5), Gotland Deep (BY15), Landsort Deep (BY31), and in the Gulf of Finland (LL07) are depicted. The Baltic proper comprises Arkona Basin, Bornholm Basin and Gotland Basin

driven by regionalizations of one General Circulation Model (GCM) forced with two greenhouse gas emission scenarios [A1B and B1, see Nakićenović et al. (2000)]. He found that at the end of the century the oxygen conditions in the deep water of the Baltic Sea will sligthly improve. Due to increasing water temperatures the spring bloom in the northern Baltic Sea will start earlier and the cyanobacteria season will be prolonged. However, both the total phytoplankton biomass and nitrogen fixation do not change significantly.

Meier et al. (2011b) performed 16 scenario simulations based upon the delta approach assuming that only the mean seasonal cycle of the atmospheric and hydrological cycles will change. They studied four projections of future climate (two GCMs and two greenhouse gas emission scenarios, A2 and B2) combined with four socio-economic scenarios affecting nutrient loads. Meier et al. (2011b) concluded that the uncertainties caused by the driving GCMs are considerable. Depending on the chosen driving GCM, wind induced mixing and, consequently, bottom oxygen concentrations will change even if river nutrient concentrations are assumed to be unchanged. In all studied scenario simulations phytoplankton concentrations in the southwestern Baltic increase in future climate. However, the model response in the northern Gotland Basin differs considerably.

In this study we further investigate uncertainties in projections of the Baltic environment from the statistics of an ensemble of 16 transient simulations including also differing nutrient load scenarios. Regionalized data by Meier et al. (2011c) from four scenario simulations driven by two GCMs and two greenhouse gas emission scenarios [A1B and A2, see Nakićenović et al. (2000)] are used to force a state-of-the-art coupled physical-biogeochemical model of the Baltic Sea (Meier et al. 2003; Eilola et al. 2009). These four climate scenarios are combined with four nutrient load scenarios suggested by HELCOM (2007): a reference scenario assuming present-day nutrient concentrations in the rivers, a pessimistic business-as-usual scenario assuming an exponential growth in agriculture in all Baltic Sea countries, a scenario of riverine nutrient loads and atmospheric deposition according to current legislations and a more optimistic case following the Baltic Sea Action Plan (BSAP) (Gustafsson et al. 2011).

In this study the approach by Meier et al. (2011b) is further refined by taking new, high-resolution model versions and time-dependent (transient) scenario simulations for the twenty first century into account. No assumptions on changes of the variability and no restriction on selected time slices in present and future climates (like in the delta approach) were made. Compared to Meier et al. (2011b) the horizontal and vertical resolutions are considerably increased.

The paper is organized as follows: In the next section the method of the dynamical downscaling approach and the involved models are briefly introduced. In the third section results of annual or seasonal mean changes of selected ecological quality indicators are presented and discussed. The results of cause-and-effect studies identifiy the dominating drivers of the simulated changes. Finally, some conclusions of the study are highlighted.

\section{Methods}

\subsection{Physical model}

We have used the three-dimensional circulation model RCO, the Rossby Centre Ocean model. RCO is a BryanCox-Semtner primitive equation circulation model with a free surface and open boundary conditions in the northern Kattegat, see Fig. 1 (Webb et al. 1997; Killworth et al. 
1991). It is coupled to a Hibler-type sea ice model with elastic-viscous-plastic rheology (Hunke and Dukowicz 1997). Subgrid-scale vertical mixing is parameterized using a turbulence closure scheme of the $\mathrm{k}-\varepsilon$ type (Rodi 1980) with flux boundary conditions to include the effect of a turbulence enhanced layer due to breaking surface gravity waves and a parameterization for breaking internal waves (Meier 2001). In the present study, RCO was used with a horizontal resolution of $3.7 \mathrm{~km}$ ( 2 nautical miles) and with 83 vertical levels with layer thicknesses of $3 \mathrm{~m}$. A fluxcorrected, monotonicity preserving transport (FCT) scheme is embedded (Gerdes et al. 1991) and no explicit horizontal diffusion is applied. For further details of the RCO model the reader is refered to Meier (2001, 2007), Meier et al. (2003).

\subsection{Biogeochemical model}

The Swedish Coastal and Ocean Biogeochemical model [SCOBI, e.g. Eilola et al. (2009)] is coupled to the physical model RCO. SCOBI describes the dynamics of nitrate, ammonium, phosphate, phytoplankton, zooplankton, detritus, and oxygen. Here, phytoplankton consists of three algal groups representing diatoms, flagellates and others, and cyanobacteria (corresponding to large, small and nitrogen fixing cells). Besides the possibility to assimilate inorganic nutrients the modelled cyanobacteria also has the ability to fix molecular nitrogen which may constitute an external nitrogen source for the model system. The sediment contains nutrients in the form of benthic nitrogen and benthic phosphorus including aggregated process descriptions for oxygen dependent nutrient regeneration, denitrification and adsorption of ammonium to sediment particles, as well as permanent burial of organic matter. With the help of a simplified wave model the combined effect of waves and current induced shear stress is considered to calculate resuspension of organic matter (Almroth-Rosell et al. 2011). For further details of the SCOBI model the reader is refered to Marmefelt et al. (1999), Eilola et al. (2009, 2011), Almroth-Rosell et al. (2011).

\subsection{Regional climate data sets}

Four climate change scenario simulations have been performed. The forcing was calculated applying a dynamical downscaling approach using the regional climate model RCAO [Rossby Centre Atmosphere Ocean model, see Döscher et al. (2002)] with lateral boundary data from two GCMs. The two GCMs used were HadCM3 from the Hadley Centre in the UK (Gordon et al. 2000) and ECHAM5/MPI-OM from the Max Planck Institute for Meteorology in Germany (Roeckner et al. 2006; Jungclaus et al. 2006), henceforth short ECHAM5. HadCM3 and
ECHAM5 simulations were forced with one (A1B) or two (A1B and A2) greenhouse gas emission scenarios, respectively. In addition, for our scenario simulations two realizations of ECHAM5 forced with the emission scenario A1B, denoted with -r1 and -r3 (ECHAM5-r1-A1B and ECHAM5r3-A1B), with differing initial conditions in the year 2000 were used. [The Max Planck Institute performed also a third realization, ECHAM5-r2-A1B, which is not used here, see Kjellström et al. (2011)]. Thus, the atmospheric forcing for RCO-SCOBI is calculated from RCAO-HadCM3-A1B, RCAO-ECHAM5-r3-A1B，RCAO-ECHAM5-r1-A1B and RCAO-ECHAM5-r1-A2.

Future projections refer to a period at the end of this century (2070-2099). Annual and seasonal mean changes were calculated from the differences between the periods 2070-2099 and 1978-2007. For further details of the downscaling method and the quality of the atmospheric forcing fields the reader is refered to Meier et al. (2011c). In contrast to earlier studies by Meier (2006) and Meier et al. (2011b) no bias correction of the atmospheric forcing was applied. An exception is the wind speed in $10 \mathrm{~m}$ height. Following Höglund et al. (2009), the wind speed is modified using simulated gustiness to improve wind speed extremes (Meier et al. 2011c).

\section{4 $\mathrm{SSH}$ at the open boundaries}

Following Gustafsson and Andersson (2001), sea surface height (SSH) in Kattegat is estimated from the daily averaged meridional atmospheric pressure gradient difference $\Delta P$ between two grid points located in The Netherlands and Norway. Thus, $\Delta P_{n}$ and $\Delta P_{n+1}$ are defined as the meridional pressure gradients at day $n$ and day $n+1$, respectively. The $\mathrm{SSH} \eta$ at day $n$ is calculated from

$\eta(n)=\alpha \Delta P(n)+\beta \Delta P(n-1)$.

The coefficients $\alpha$ and $\beta$ are computed using a simple optimisation method in order to get the best possible fit to sea level observations in Smögen located at the Swedish west coast close to the open boundary of the model domain in Kattegat. For the optimisation procedure atmospheric pressure data from the Rossby Centre Atmosphere model [RCA, Samuelsson et al. (2011)] driven with ERA40 re-analysis data (Uppala et al. 1989) at the lateral boundaries are used. This approach provides a good correlation of calculated and observed SSHs, but the calculated standard deviations are too small compared to observations. The probability density function reveals that positive extremes of $\mathrm{SSH}$ are underestimated (not shown). These extremes are essential for salt water inflows into the Baltic Sea.

If the calculated $\mathrm{SSH}$ is used as forcing for the Baltic Sea model, the overall salinity of the Baltic Sea will 
decrease unrealistically. We suspect that this shortcoming of the estimated SSH is related to underestimated atmospheric depressions in RCA causing an underestimation of the meridional pressure gradient variability.

In order to overcome this problem, estimated SSH data are bias corrected using statistical information from the observations. $\eta_{\text {sim }}(n)$ and $\eta_{o b s}(n)$ are discrete values of simulated and observed SSH for a given period of time containing $N$ time steps $(1 \leq n \leq N)$. Further, $O\left(\eta_{\text {sim }}(n)\right)$ and $O\left(\eta_{o b s}(n)\right)$ are defined as sorted discrete functions applied to $\eta_{\text {sim }}(n)$ and $\eta_{o b s}(n)$, respectively. A third function $F$ is defined by the relation

$O\left(\eta_{\text {obs }}(n)\right)=F\left[O\left(\eta_{\text {sim }}(n)\right)\right]$.

$F$ is calculated from the relation of $O\left(\eta_{\text {sim }}(n)\right)$ and $O\left(\eta_{o b s}\right.$ (n)) using a polynomial function as approximation. We choose a 3rd order polynomial function with coefficients estimated from a simple optimisation method. The bias corrected $\eta_{\text {sim }}(n)$ is given as

$\eta_{\text {sim-corr }}(n)=F\left[\eta_{\text {sim }}(n)\right]$.

The variability of $\eta_{\text {sim-corr }}(n)$ is much closer to that of $\eta_{o b s}(n)$ and the correlation between estimated and observed SSH is slightly larger. Using $\eta_{\text {sim-corr }}(n)$ instead of $\eta_{\text {sim }}(n)$ as forcing at the lateral boundary in Kattegat improves the simulated Baltic Sea salinity during present climate. The agreement between the probability density functions of the reconstructed and corrected SSH and the observations is very good (not shown).

In the transient simulations we applied the correction both in past and future climates assuming that the statistical relationship will not change with time.

\subsection{Runoff}

Runoff is calculated with a statistical method which is applied to estimate river flows from the net water budget (precipitation minus evaporation) over the Baltic drainage area as simulated with RCAO because for our experiments results from a hydrological model were not available.

The net water budget in RCA is realistically simulated (Lind and Kjellström 2009; Kjellström and Lind 2009). For the scenario simulations only the variability of annual mean runoff anomalies is calculated. We do not consider changes of the seasonal cycle of the runoff because their impact on the large-scale salinity distribution in the Baltic Sea is small (Meier and Kauker 2003).

Our method assumes that the annual mean runoff from a given drainage area $p$ during the year $n$ is correlated with the net water budget anomaly (in \%) over this given water area during the given year and the one before:

$R_{p, n}=b_{p} B_{p, n-1}+a_{p} B_{p, n}$ in which $R_{p, n}$ is the runoff for the year $n$ and for the drainage area $p . B_{p, n}$ is the net water budget (precipitation minus evaporation) anomaly for year $n$ and area $p$. Finally, $b_{p}$ and $a_{p}$ are two coefficients. Five different drainage areas are considered, i.e. the drainage areas of the Bothnian Bay, Bothnian Sea, Gulf of Finland, Baltic proper and Kattegat (Fig. 1). The statistical model is constrained for present climate when reliable observations of the annual mean runoff anomaly are available (Bergström and Carlsson 1994). $b_{p}$ and $a_{p}$ are determined using an optimisation method during 1980-2006.

During 1960-1979 the statistical model is validated when both runoff observations and simulation results from RCA driven by ERA40 are available. Figure 2 shows the results of the statistical model for 1960-2006 for the Baltic proper. The results are satisfactory except for the Gulf of Finland and the Gulf of Riga (Table 1). The annual variability is fairly well reproduced for the entire Baltic Sea although it is obvious that the standard deviation of the re-constructed runoff is smaller than the standard deviation of the observations (not shown).

It is assumed that the statistical relationship between runoff and precipitation minus evaporation does not change in time.

\subsection{Nutrient loads scenarios}

Nutrient loads from rivers are calculated from the product of the nutrient concentration and the volume flow (Sect. 2.5) following Stålnacke et al. (1999), see Eilola et al. (2009) and Meier et al. (2011b). Thus, it is assumed that the nutrient reservoir on land will be large enough to provide increased nutrient loads during the integration period if the volume flows increase. Four scenarios are considered:

- REFerence (REF): current nutrient concentrations in rivers and current atmospheric deposition (see Eilola et al. 2009),

- Current LEGislation (CLEG): riverine nutrient concentrations according to legislation on sewage water

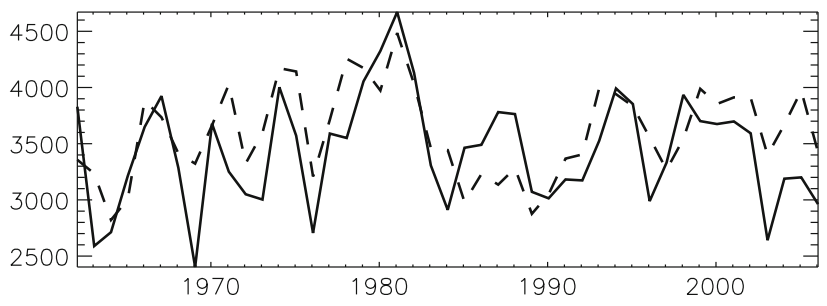

Fig. 2 Interannual variability of observed (solid line) and reconstructed (dashed line) annual mean runoff (in $\mathrm{m}^{3} \mathrm{~s}^{-1}$ ) in the Baltic proper 
Table 1 Squared correlation coefficients between simulated and observed runoff for 1962-2006 in different sub-basins

\begin{tabular}{lllllll}
\hline & BB & BS & GF & GR & BP & Total \\
\hline $\mathrm{r}^{2}$ & 0.44 & 0.36 & 0.10 & 0.01 & 0.40 & 0.40 \\
\hline
\end{tabular}

$B B$ Bothnian Bay, $B S$ Bothnian Sea, $G F$ Gulf of Finland, $G R$ Gulf of Riga, $B P$ Baltic proper, Total Baltic Sea with Kattegat

treatment (EU wastewater directive) and $25 \%$ reduction of atmospheric nitrogen,

- Baltic Sea Action Plan (BSAP): reduced riverine nutrient concentrations following HELCOM (2007) and $50 \%$ reduced atmospheric deposition,

- Business-As-Usual (BAU): business-as-usual for nutrient concentrations in rivers assuming an exponential growth of agriculture in all Baltic Sea countries following HELCOM (2007) and current atmospheric deposition.

A summary of the assumptions behind these nutrient load scenarios can be found in HELCOM (2007) based upon Wulff et al. (2007) and Humborg et al. (2007), while a comprehensive description of the calculation of the actual load changes is given in Gustafsson et al. (2011).

The averaging period for the reference river load concentration is 1995-2002. This excludes some years in the early 2000s with abnormal nutrient loads. Load changes are applied on the total loads (not only on bioavailable fractions). Table 2 shows the nutrient concentration changes beyond the year 2020 for the different scenarios calculated by Gustafsson et al. (2011).

For the transient scenario simulations the future nutrient input into the Baltic Sea is represented by piecewise linear ramp functions. We run RCO-SCOBI until the end of 2007, ramp to the end of 2020 and then use constant nutrient concentrations in the rivers according to BSAP, CLEG and BAU (for REF the nutrient concentrations are constant with time). Coastal point sources are lumped into the river loads. The same functional form is used for the atmospheric deposition of nutrients.

These socio-economic scenarios are combined with the four climate scenarios described in Sect. 2.3. The 16 transient simulations are summarized in Table 3. Following Meier (2006) and Meier et al. (2011b), in all scenario simulations lateral boundary conditions in the northern Kattegat are unchanged assuming that especially Kattegat deep water properties will not change in future.

\subsection{Cause-and-effect studies}

In addition to scenario simulations, we performed causeand-effect studies with climatological mean seasonal cycles for air temperature and specific humidity fields or
Table 2 Scenarios of nutrient concentration changes in the rivers in $\%$ per sub-basin following Gustafsson et al. (2011)

\begin{tabular}{lrlllllll}
\hline & \multicolumn{1}{l}{ KA } & DS & BP & BS & BB & GR & GF & Sum \\
\hline BSAP N & -30.0 & -32.7 & -25.6 & 0.0 & 0.0 & 0.0 & -5.6 & -17.5 \\
BSAP P & 0.0 & 0.0 & -56.9 & 0.0 & 0.0 & -17.9 & -23.0 & -35.1 \\
CLEG N & -0.1 & -0.3 & -4.4 & 0.0 & 0.0 & 0.0 & -5.3 & -2.9 \\
CLEG P & 0.0 & 0.0 & -20.1 & 0.0 & 0.0 & -15.3 & -15.1 & -14.7 \\
BAU N & 0.0 & 0.0 & 62.6 & 0.0 & 0.0 & 62.6 & 62.6 & 44.1 \\
BAU P & 0.0 & 0.0 & 46.1 & 0.0 & 0.0 & 46.1 & 46.1 & 37.0 \\
\hline
\end{tabular}

Coastal point sources are included in these concentration changes. The changes refer to differences of concentrations for nitrogen $(\mathrm{N})$ and phosphorus $(\mathrm{P})$ beyond 2020 and prior to 2007

$K A$ Kattegat, $D S$ Danish Straits, $B P$ Baltic proper, $B S$ Bothnian Sea, $B B$ Bothnian Bay, GR Gulf of Riga, $G F$ Gulf of Finland

Table 3 Weights used to calculate the ensemble mean from 16 transient simulations for 1961-2099

\begin{tabular}{lllll}
\hline Climate versus nutrient scenarios & BSAP & CLEG & REF & BAU \\
\hline HadCM3-A1B & $1 / 2$ & $1 / 2$ & $1 / 2$ & $1 / 2$ \\
ECHAM5-r3-A1B & $1 / 6$ & $1 / 6$ & $1 / 6$ & $1 / 6$ \\
ECHAM5-r1-A1B & $1 / 6$ & $1 / 6$ & $1 / 6$ & $1 / 6$ \\
ECHAM5-r1-A2 & $1 / 6$ & $1 / 6$ & $1 / 6$ & $1 / 6$ \\
\hline
\end{tabular}

The abbreviations are explained in the text

with climatological mean river discharges after year 2007 . Thus, in the first set of experiments (henceforth TAIRCLIM) water temperatures do not increase during the twenty first century compared to the reference period 1969-1998. In the second set of experiments (henceforth RUNOFFCLIM) salinities do not decrease and nutrient transports from land only alter with changing nutrient concentrations depending on the applied socio-economic scenario because annual mean volume flows do not change with time.

\subsection{Analysis strategy}

We focus on annual and seasonal mean changes of selected climate parameters and ecological quality indicators describing changes of the atmospheric and hydrological forcing and changes of the physical and environmental status of the Baltic Sea like air temperature, maximum estimated gust wind, river discharge, nutrient loads from land to the sea, water temperature, salinity, and oxygen, phosphate, nitrate and phytoplankton concentrations.

Further, Secchi depth $\left(\mathrm{S}_{d}\right)$ is calculated from $\mathrm{S}_{d}=$ $1.7 / \mathrm{k}(\mathrm{PAR})$, where $\mathrm{k}(\mathrm{PAR})$ is the coefficient of underwater attenuation of the photosynthetically available radiation 
(Kratzer et al. 2003). Factors controlling light attenuation in the Baltic Sea model are the concentrations of phytoplankton and detritus. Thereby, the total phytoplankton concentration is the sum of the three algal groups represented in SCOBI (Sect. 2.2). In the scenario simulations changes of the Secchi depth are given by changing phytoplankton and detritus concentrations.

For the calculation of Secchi depth it is assumed that yellow substances (or colored dissolved organic material, CDOM) are constant in time and will not increase in future. This assumption is probably not true because available observations indicate that in regions with salinities below 2-3 $\mathrm{g} \mathrm{kg}^{-1}$ concentrations of CDOM are considerably larger than in other regions with higher salinities. Hence, it might be that decreasing salinities in future will cause increasing concentrations of yellow substances in the gulfs and in coastal zones affecting light climate for phytoplankton. Thus, there might be a non-linear impact of increasing yellow substances and changing phytoplankton and detritus concentrations on Secchi depth. As details of processes and future trends are unknown, the impact of possible changes of yellow substances is not considered in our scenario simulations.

As wind speed extremes in regional climate models like RCAO are usually underestimated, a modification of the 10 $\mathrm{m}$ wind is applied to guarantee correctly simulated wind induced mixing in the ocean (Meier et al. 2011c). Following Meier et al. (2011c) both the maximum $10 \mathrm{~m}$ wind speed and the maximum estimated gust wind are used to calculate wind speed extremes. In RCAO the maximum $10 \mathrm{~m}$ wind speed is calculated following the MoninObukhov similarity theory (Monin and Obukhov 1954) and is interpolated from the lowest atmospheric level $(90 \mathrm{~m})$ down to $10 \mathrm{~m}$. The maximum estimated gust wind is calculated from the turbulent kinetic energy equation following Brasseur (2001). In RCAO the gust winds can propagate down to the surface from all boundary layer levels if the mixing is strong enough. For both parameters the absolute maximum over the output interval of three hours is stored while the internal time step is $15 \mathrm{~min}$ for $25 \mathrm{~km}$ resolution (Samuelsson et al. 2011). In general, the estimated gust wind is larger than the maximum $10 \mathrm{~m}$ wind speed. Thus, in this study we focus on the analyis of changes of the mean maximum estimated gust wind.

To analyse the response of ocean parameters we calculated ensemble mean fields from the four climate projections. As our ensemble consists of one HadCM3 and three ECHAM5 driven simulations, we weighted the ensemble members such that both GCMs are equally represented within the ensemble mean (Table 3). As we have only four ensemble members, the ensemble spread is illustrated by the difference between the maximum and minimum values of the four simulations. As the ensemble is too small, the calculation of the standard deviation would not be a good measure to characterize the spread.

\section{Results}

\subsection{Evaluation of the control climate}

The quality of the atmospheric forcing was assessed by Meier et al. (2011c). Meier et al. (2011a) compared results of the climate simulations during the control period with hindcast simulations forced with regionalized ERA40 data (Samuelsson et al. 2011). Here, we focus on ocean modeling results of the four transient simulations at selected monitoring stations in the Baltic proper and Gulf of Finland (Fig. 1). Figure 3 shows simulated and observed mean vertical profiles of water temperature, salinity, oxygen, phosphate, and nitrate concentrations at Bornholm Deep (BY5), Gotland Deep (BY15), Landsort Deep (BY31) and in the western Gulf of Finland (LL07). For the control period 1978-2007 the agreement between model results and observations is satisfactory. In ECHAM5 driven simulations the resulting mean vertical profiles of salinity, oxygen, phosphate and nitrate are close to observations. Most of the biases are within the range of natural variability of the observations. The quality of the HadCM3 driven simulation is worse although mean vertical temperature profiles are slightly better reproduced in the HadCM3 driven simulation than in ECHAM5 driven simulations because of a warm bias in ECHAM5 over the Baltic Sea (Meier et al. 2011c).

\subsection{Climate scenarios}

\subsubsection{Atmospheric variables}

Table 4 summarizes the mean temperature and precipitation changes of RCAO over the Baltic Sea region. The largest increase of the $2 \mathrm{~m}$ air temperature is found in the northern Baltic Sea in particular during winter and spring (Fig. 4). Within the ensemble the largest increase occurs in the HadCM3 driven simulation with the A1B greenhouse gas emission scenario and not in the ECHAM5 driven simulation with the A2 emission scenario (not shown). Meier et al. (2011c) showed that a warm bias of the control climate (1969-1998) in ECHAM5 driven simulations reduces the ice-albedo feedback. Hence, the climate change signal is smaller compared to the HadCM3 driven simulation. In the three ECHAM5 driven simulations the horizontal patterns of the air temperature changes are very similar. Thus, we depict only results from RCAOECHAM5-r1-A1B. 

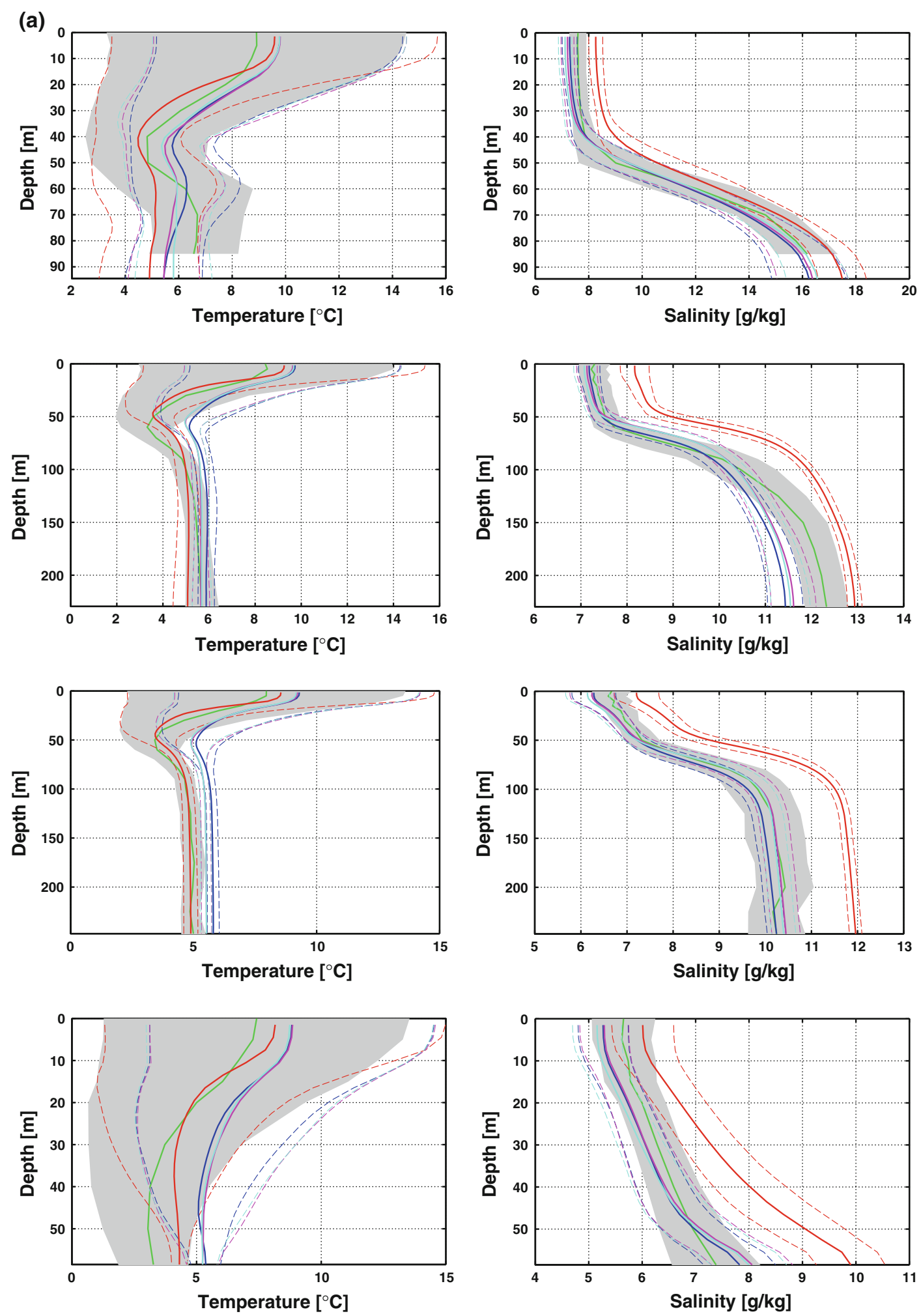

Fig. 3 a Mean (1978-2007) temperature (in ${ }^{\circ} \mathrm{C}$, left panels) and salinity (in $\mathrm{g} \mathrm{kg}^{-1}$, right panels) at the monitoring stations BY5, BY15, BY31 and LL07 (from top to bottom): observations (green), HadCM3-A1B (red), ECHAM5-r3-A1B (blue), ECHAM5-r1-A1B (magenta) and ECHAM5-r1-A2 (cyan). The range of variability is indicated by the \pm 1 standard deviation band calculated from 2-daily

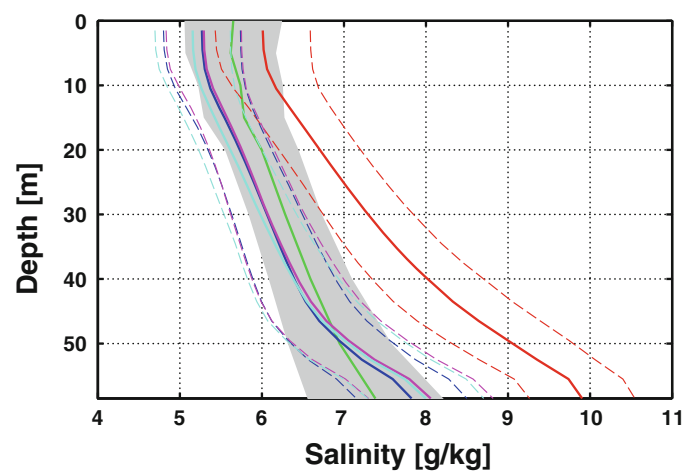

model output (dashed curves) or from observations (grey shaded area) from the Baltic Environmental Database (BED) at the Baltic Nest Institute (http://nest.su.se/bed). b As (a) but for phosphate (in $\mu$ mol $\mathrm{P}^{-1}$, left panels) and nitrate (in $\mu \mathrm{mol} \mathrm{N}^{-1}$, right panels). c As (a) but for oxygen (in $\mathrm{ml} \mathrm{l}^{-1}$ ) 
(b)
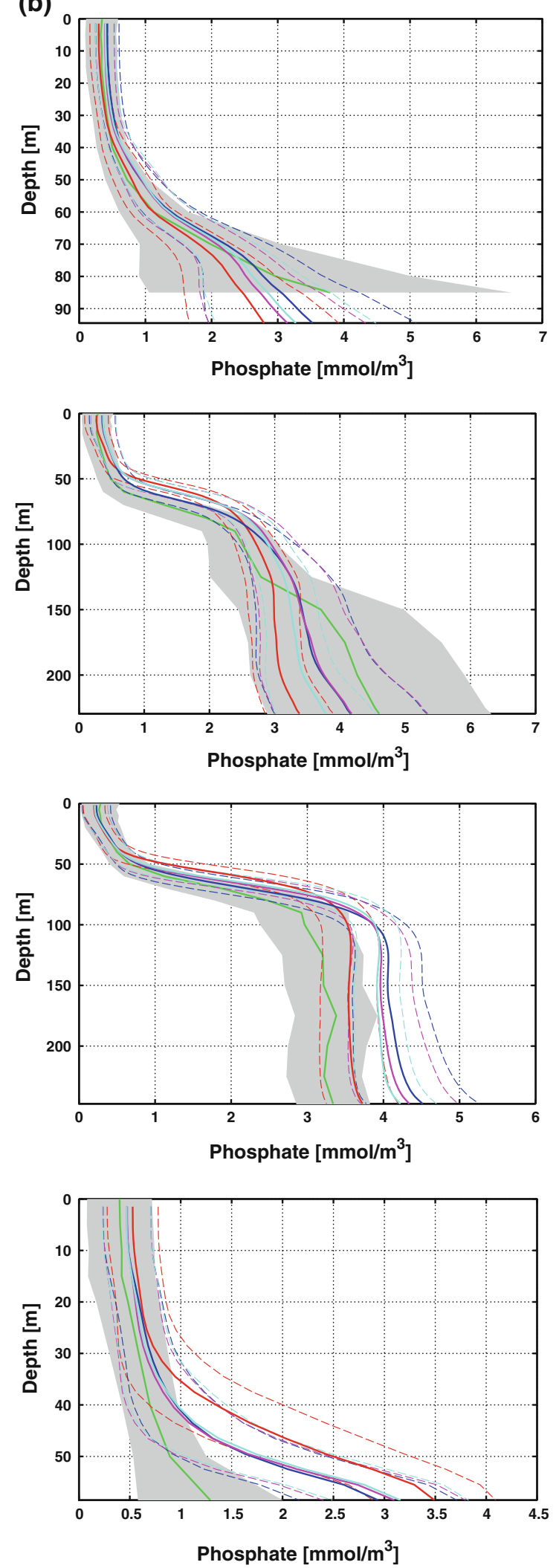
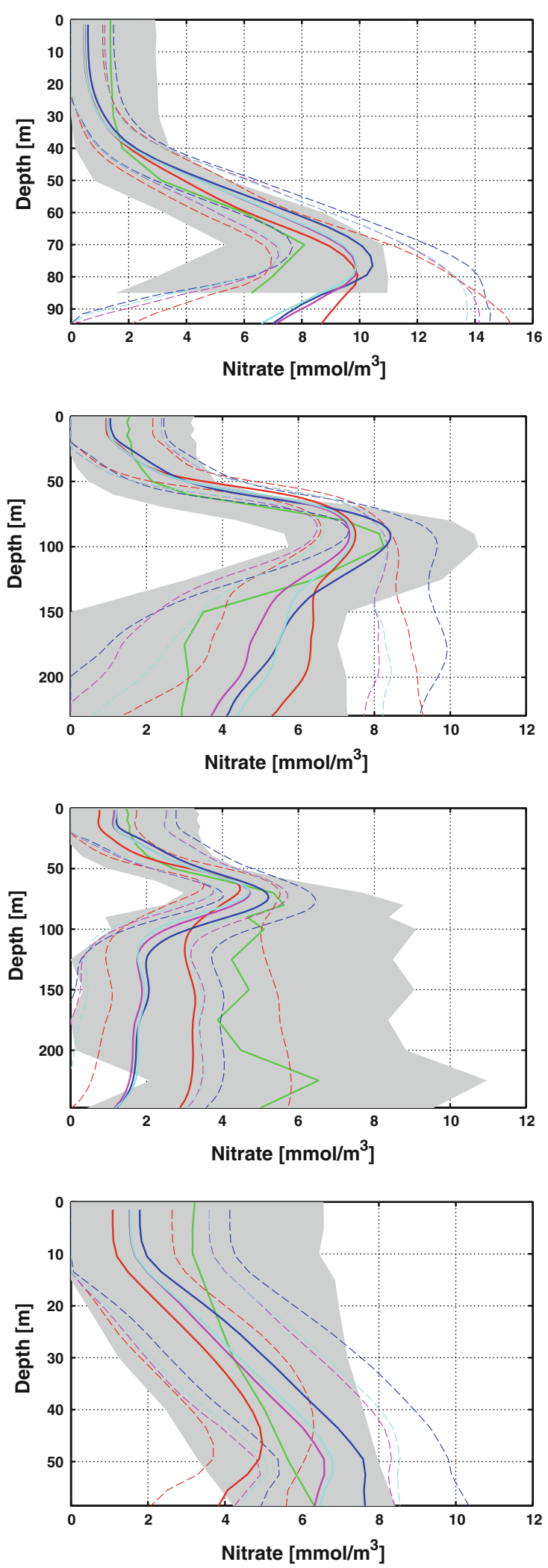

Fig. 3 continued 

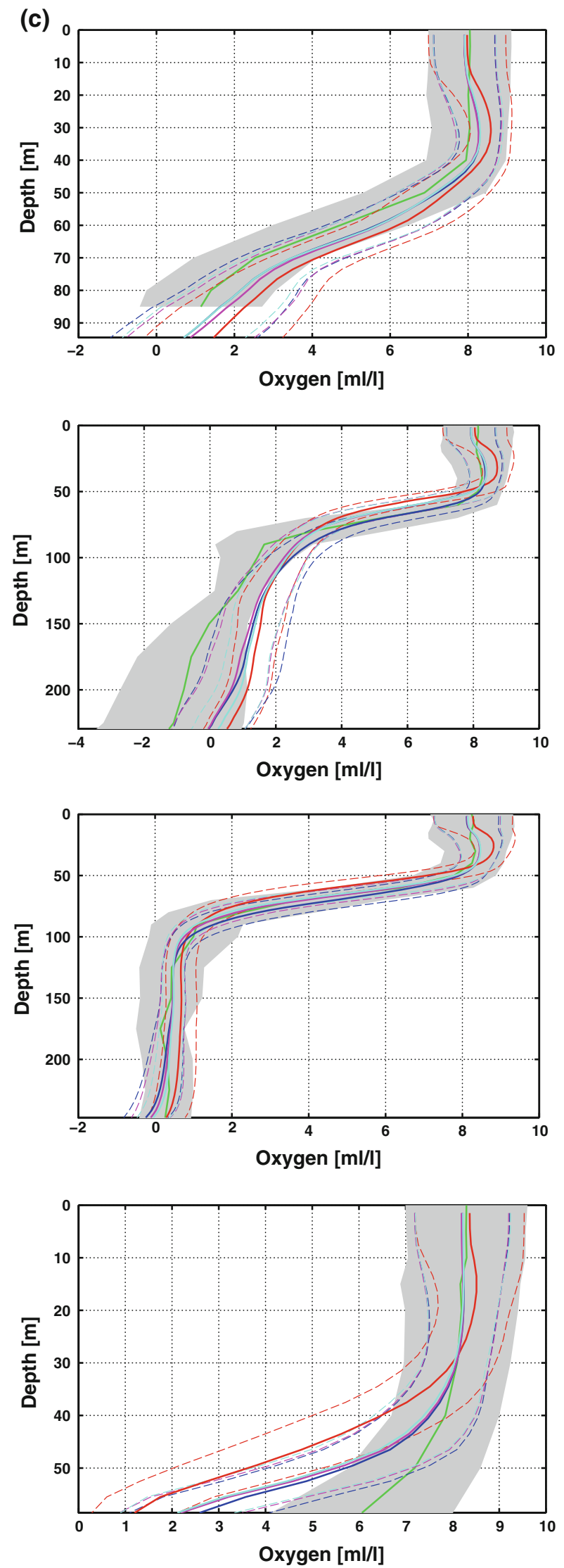

Fig. 3 continued
Table 4 Mean temperature (in ${ }^{\circ} \mathrm{C}$ ) and precipitation (in \%) changes over the Baltic Sea region for 2070-2099 relative to 1969-1998

\begin{tabular}{lllll}
\hline Experiment & $\begin{array}{l}\text { HadCM3- } \\
\text { A1B }\end{array}$ & $\begin{array}{l}\text { ECHAM5- } \\
\text { r3-A1B }\end{array}$ & $\begin{array}{l}\text { ECHAM5- } \\
\text { r1-A1B }\end{array}$ & $\begin{array}{l}\text { ECHAM5- } \\
\text { r1-A2 }\end{array}$ \\
\hline Temperature & +3.8 & +2.7 & +2.8 & +2.8 \\
Precipitation & +18 & +12 & +17 & +17 \\
\hline
\end{tabular}

Although regional details and the overall magnitude may differ, in all experiments the sea level pressure (SLP) will get more zonal at the end of the century (not shown). These results of RCAO are in accordance with results by Kjellström et al. (2011). The largest changes of precipitation occur over the mountain areas (not shown). We found similar patterns of changing precipitation in HadCM3 and ECHAM5 driven simulations. Cloud cover changes are relatively small (not shown). During spring the cloudiness will slightly increase in ECHAM5 driven simulations. In the other seasons the cloudiness will slightly decrease over the Baltic Sea. This is a common signal in all scenario simulations.

In general, also the changes of the mean $10 \mathrm{~m}$ wind speed are small (not shown). Significantly increased mean $10 \mathrm{~m}$ wind speeds of about $1 \mathrm{~m} \mathrm{~s}^{-1}$ are found only in RCAO-ECHAM5-r1-A1B and RCAO-ECHAM5-r1-A2 in the Baltic proper during winter and autumn and in RCAOHadCM3-A1B in the Bothnian Sea during autumn.

In all simulations the maximum $10 \mathrm{~m}$ wind speed and the maximum estimated gust wind increase by more than $1 \mathrm{~m} \mathrm{~s}^{-1}$ in the Bothnian Bay and Gulf of Finland during winter and spring as a consequence of the melting sea ice in future climate (Fig. 5). In RCAO-HadCM3-A1B maximum changes exceed even $3 \mathrm{~m} \mathrm{~s}^{-1}$. However, compared to earlier results of ECHAM4 (Roeckner et al. 1999) driven regionalizations (e.g. Räisänen et al. 2004) are wind speed changes in the simulations of this study small. Hence, its consequences for stratification and oxygen conditions in the Baltic deep water are smaller than reported by Meier et al. (2011b) (see below).

\subsubsection{Runoff and nutrient loads}

Table 5 summarizes the total volume flows in present and future climates calculated with the statistical model (Sect. 2.5). We found changes of the total volume flow to the Baltic Sea between 15 and $22 \%$

In all sub-basins including the Baltic proper the volume flow changes are positive (not shown). The changes are larger in the northern sub-basins than in the southern subbasins in agreement with earlier results by Graham (2004). However, positive volume flow changes to the Baltic proper are an important difference compared to the results 

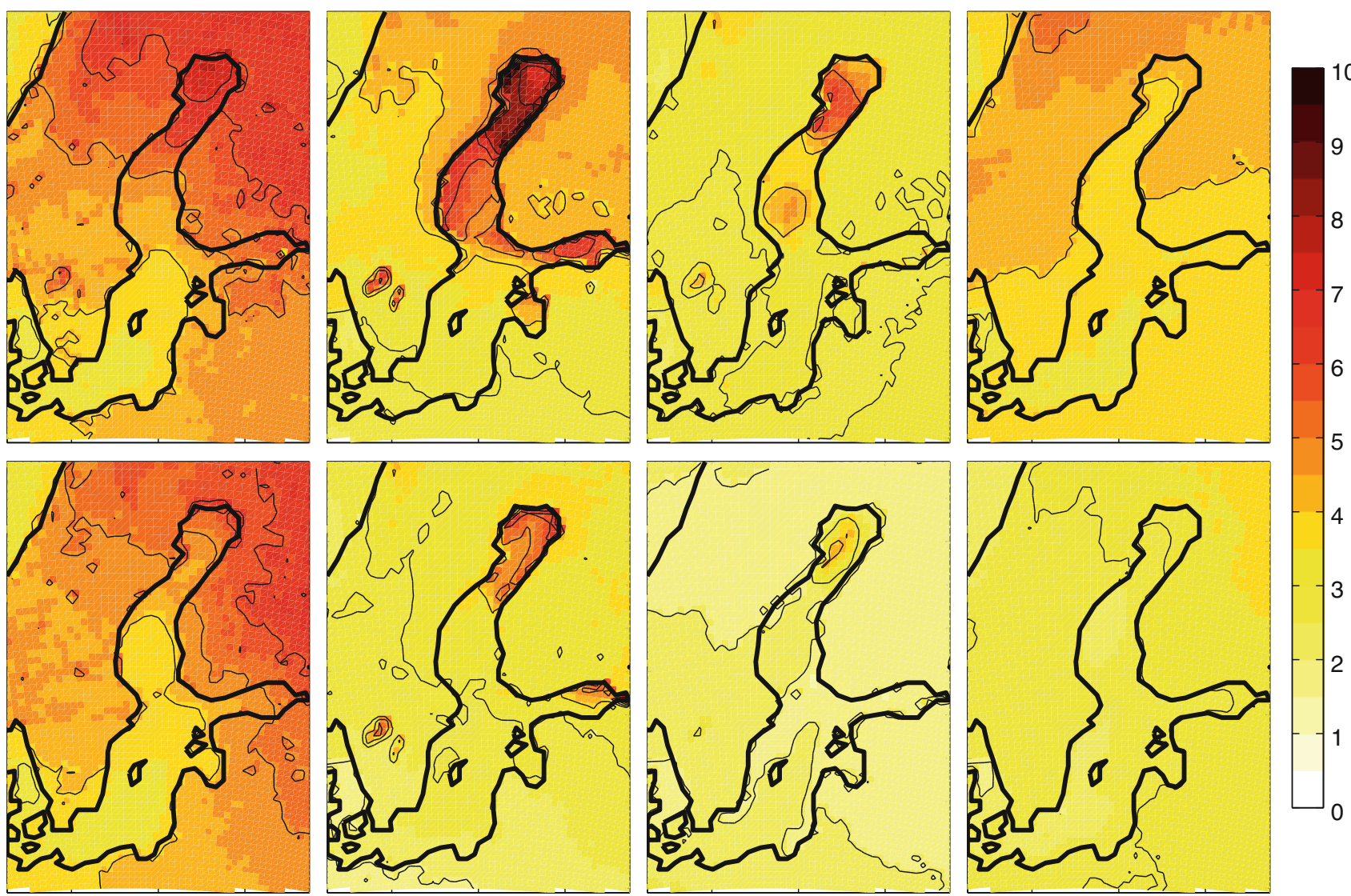

Fig. 4 Seasonal mean $2 \mathrm{~m}$ air temperature changes (in ${ }^{\circ} \mathrm{C}$ ) between the periods 2069-2099 and 1969-1998. From left to right winter (DJF), spring (MAM), summer (JJA) and autumn (SON) mean

changes are shown. The upper and lower panels show results from HadCM3-A1B and ECHAM5-r1-A1B driven simulations, respectively

by Meier et al. (2011b). In their scenario simulations volume flow changes to the Baltic proper were negative although in three out of four climate projections the total flows into the entire Baltic were positive. As nutrient loads from the Baltic proper catchment area are largest, volume flow changes to the Baltic proper control the changes of the total nutrient supply from land (assuming reference river nutrient concentrations). Thus, in the experiments by Meier et al. (2011b) the total nutrient load changes have different sign depending on the selected climate projection whereas in our study nutrient loads increase in all projections (Fig. 6). This discrepancy reflects the uncertainty of state-of-the-art hydrological modelling (Graham et al. 2007).

In Fig. 6 the absolute changes of the nutrient loads per sub-basin are shown. In the nutrient load scenario REF the biologically available phosphorus and nitrogen loads increase by about $15-20 \%$ each depending on the climate projection. These changes are about two times larger than the largest increase calculated by Meier et al. (2011b).
In the most optimistic nutrient load scenario of this study (BSAP) we found reductions of about 7-8 and 10-50 kton year $^{-1}$ for phosphorus and nitrogen, respectively (Fig. 6). However, the BSAP requires much larger reductions of 15 and $133 \mathrm{kton}_{\text {year }}{ }^{-1}$ for phosphorus and nitrogen, respectively (HELCOM 2007). Note that the latter figures for the total Baltic include Kattegat. In our simulations nutrient load reductions in the Baltic proper are partly compensated by nutrient load increases in the northern sub-basins, e.g. in the Bothnian Sea and Bothnian Bay. The reductions of the BSAP scenario by Meier et al. (2011b) are closer to the original figures by HELCOM (2007).

For the most pessimistic nutrient load scenario of this study (BAU) we found increases of about 17-19 and 440-500 kton year $^{-1}$ for phosphorus and nitrogen, respectively (Fig. 6). Following HELCOM (2007) changes according to BAU amount to 16 and $340 \mathrm{kton}^{\text {year }}{ }^{-1}$ for phosphorus and nitrogen, respectively.

Note that in the nutrient load scenario CLEG the total phosphorus load will decrease and the total nitrogen load 

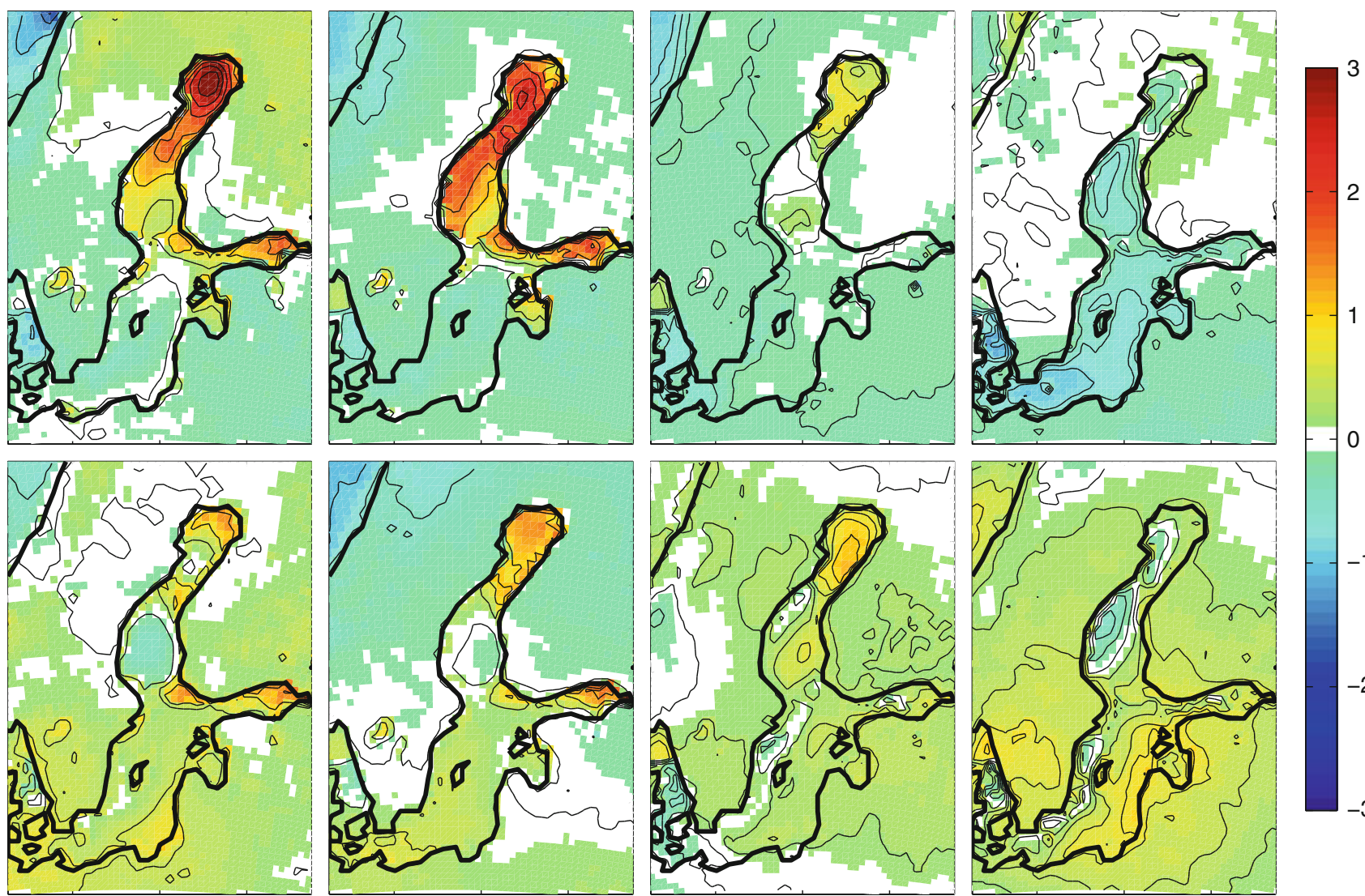

2

1 
Fig. 6 Changes of the annual mean biologically available total nitrogen (left panels) and phosphorus (right panels) loads (in $\mathrm{kton}_{\text {year }}{ }^{-1}$ between 1971-2000 and 2070-2099 in the 16 scenario simulations. $B B$ Bothnian Bay, BS Bothnian Sea, $G F$ Gulf of Finland, GR Gulf of Riga, $B P$ Baltic proper, $K A$ Kattegat (excluding the River Göta Älv), TOT total Baltic Sea (excluding Kattegat), E5A1B1 ECHAM5-r1-A1B, E5A1B3 ECHAM5-r3-A1B, E5A2 ECHAM5-r1-A2, HADA1B HadCM3-A1B

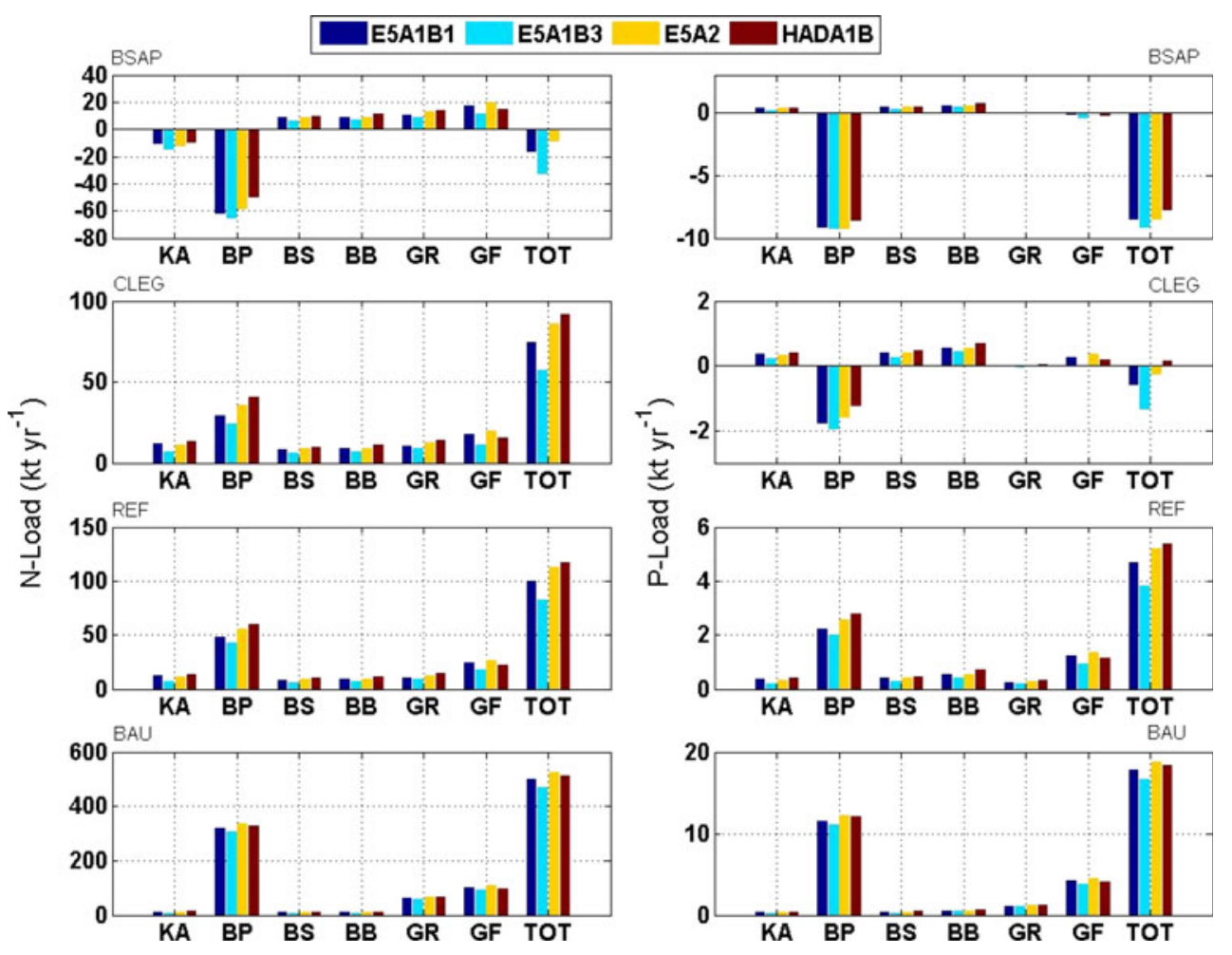

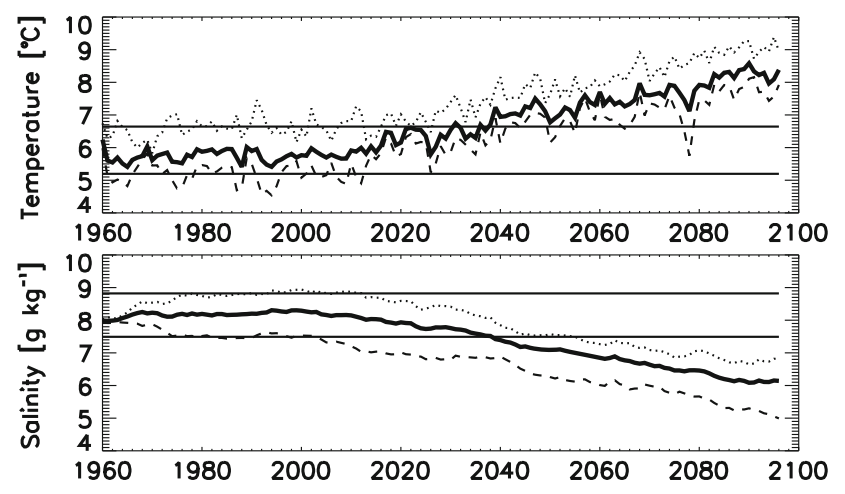

Fig. 7 Ensemble mean volume averaged temperature (in ${ }^{\circ} \mathrm{C}$, upper panel) and salinity (in $\mathrm{g} \mathrm{kg}^{-1}$, lower panel) for the entire Baltic including Kattegat (solid line). Maximum and minimum values of the ensemble are shown by dotted and dashed lines, respectively. Straight lines indicate the mean maximum and mininum values during 1978-2007

GCMs as indicated both by the standard deviation of the ensemble mean (not shown) and the ensemble spread.

We found the largest SST increases of more than $6{ }^{\circ} \mathrm{C}$ in the southern Bothnian Bay in the HadCM3 driven scenario simulation during summer. In ECHAM5 driven simulations the largest SST increase is located in the central Bothnian Bay and does not exceed $4{ }^{\circ} \mathrm{C}$ approximately. Further, in all scenario simulations the largest SST increase during winter and spring occurs in the Gulf of Finland.

Noteworthy, SST changes lag $2 \mathrm{~m}$ air temperature changes in time. Maximum air temperature changes occur in winter and spring in the Bothnian Bay, the northern Bothnian Sea and the eastern Gulf of Finland (Fig. 4). However, the largest SST signal is found in the Bothnian Bay during summer (Fig. 8). The larger warming in the northern compared to the southern Baltic is explained by the ice-albedo feedback (Meier et al. 2011b; Wang et al. 2005) and by the reduced thermal convection under warmer and fresher conditions (Hordoir and Meier 2011).

Also spatial patterns of sea surface salinity (SSS) projections show an overall agreement with largest decreases in the Baltic proper of about $1.5-2 \mathrm{~g} \mathrm{~kg}^{-1}$ (not shown). Salinity is reduced because in all scenario simulations runoff is significantly increased. Changes of the wind speed are of minor importance for SSS changes. Largest discrepancies between scenario simulations are found for the SSS projections in Kattegat.

Changes of bottom salinity concentrations follow SSS changes (not shown). As in the ECHAM5-r1-A1B and A2 driven simulations maximum wind speeds increase in particular over the Bothnian Bay and Gulf of Finland but also over the Baltic proper (Fig. 5), wind induced mixing is larger in future climate and the permanent halocline is deeper located. Consequently, we found largest bottom salinity changes along the slopes of the Baltic proper and Gulf of Finland at depths of the halocline changes. As the wind changes occur only in two out of four scenario simulations of our mini-ensemble, the largest spread of projected bottom salinity is related to the different depth of the halocline in the four simulations. 

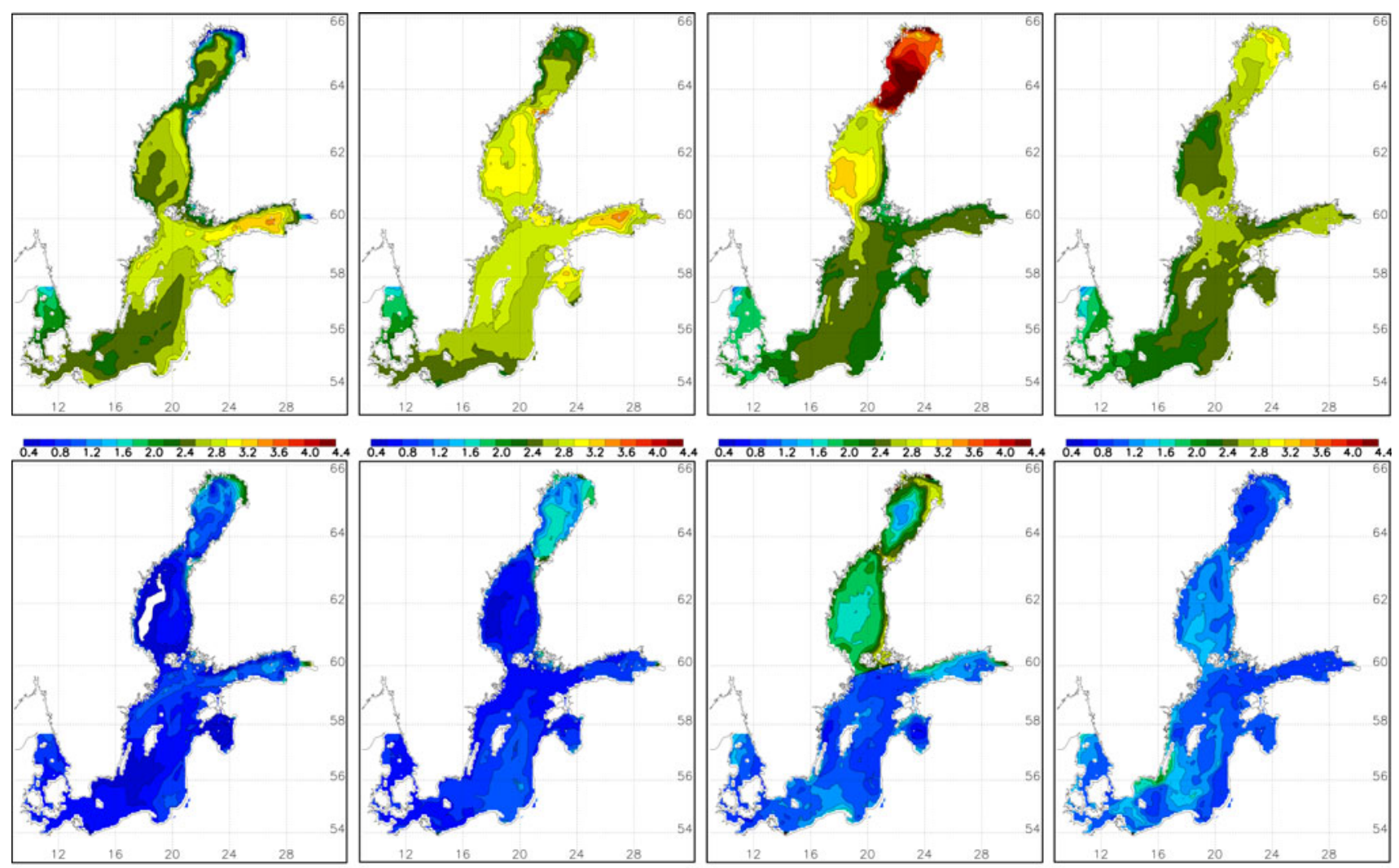

$\begin{array}{lllllllllll}0.4 & 0.8 & 1.2 & 1.6 & 2.0 & 2.4 & 2.8 & 3.2 & 3.6 & 4.0 & 4.4\end{array}$

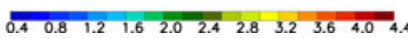

Fig. 8 Seasonal mean sea surface temperature (SST) changes (in ${ }^{\circ} \mathrm{C}$ ) between 2070-2099 and 1978-2007 in RCO-SCOBI simulations driven by regionalized GCM results. From left to right winter (December-February), spring (March-May), summer (June-August)

and autumn (September-November) mean changes are shown. The upper and lower panels show the ensemble mean and the ensemble range, respectively. Values larger than $4.4{ }^{\circ} \mathrm{C}$ or smaller than $0.4{ }^{\circ} \mathrm{C}$ are depicted in brown or white, respectively

\subsection{Socio-economic scenarios}

After the spinup of about 10 years at the beginning of the simulations the dissolved inorganic nitrogen (DIN) pool is constant during the control period (not shown). After 2007 DIN increases in the scenario simulations REF and BAU and decreases in BSAP (about constant in CLEG) (Fig. 9). In all nutrient load scenarios dissolved inorganic phosphorus (DIP) increases during the control period which is consistent with the hindcast simulation (Meier et al. 2011a). After 2007 DIP increases in REF and BAU and decreases in BSAP (about constant in CLEG). The results confirm the much longer time scale of the phosphorus cycle compared to the nitrogen cycle.

Interestingly, the sediment pools of nitrogen and phosphorus decrease in almost all scenarios towards the end of the twenty first century (Fig. 9). Only in BAU nitrogen and phosphorus concentrations in the sediments increase between 2007 and 2050 approximately. After 2050 both concentrations either decrease (nitrogen) or remain relatively constant (phosphorus).

In all scenarios there is a tendency of increased DIN to DIP ratio in the water column (not shown). Especially in the BSAP scenario driven by ECHAM5-r1-A2 and ECHAM5-r1-A1B (the scenario simulations with an increase of the wind speed over the Baltic proper, see Fig. 5) the overall DIN to DIP ratios increase with about 7 and 5, respectively. Thus, the Baltic proper will switch from a nitrogen limited to a phosphorus limited ecosystem in agreement with the results by Meier et al. (2011b).

\subsubsection{Projected changes for REF}

In the reference scenario (REF) the bottom oxygen concentrations decrease in all climate projections in almost all regions (Fig. 10). Exceptions are the deep water in the Gulf of Finland and regions along the slopes of the Gotland Basin where the stratification decreases due to a deeper halocline caused by increased runoff (in all climate projections, Table 5) and increased wind speed (in ECHAM5r1-A1B and ECHAM5-r1-A2 driven simulations, Fig. 5). As the oxygen saturation concentration is smaller in 

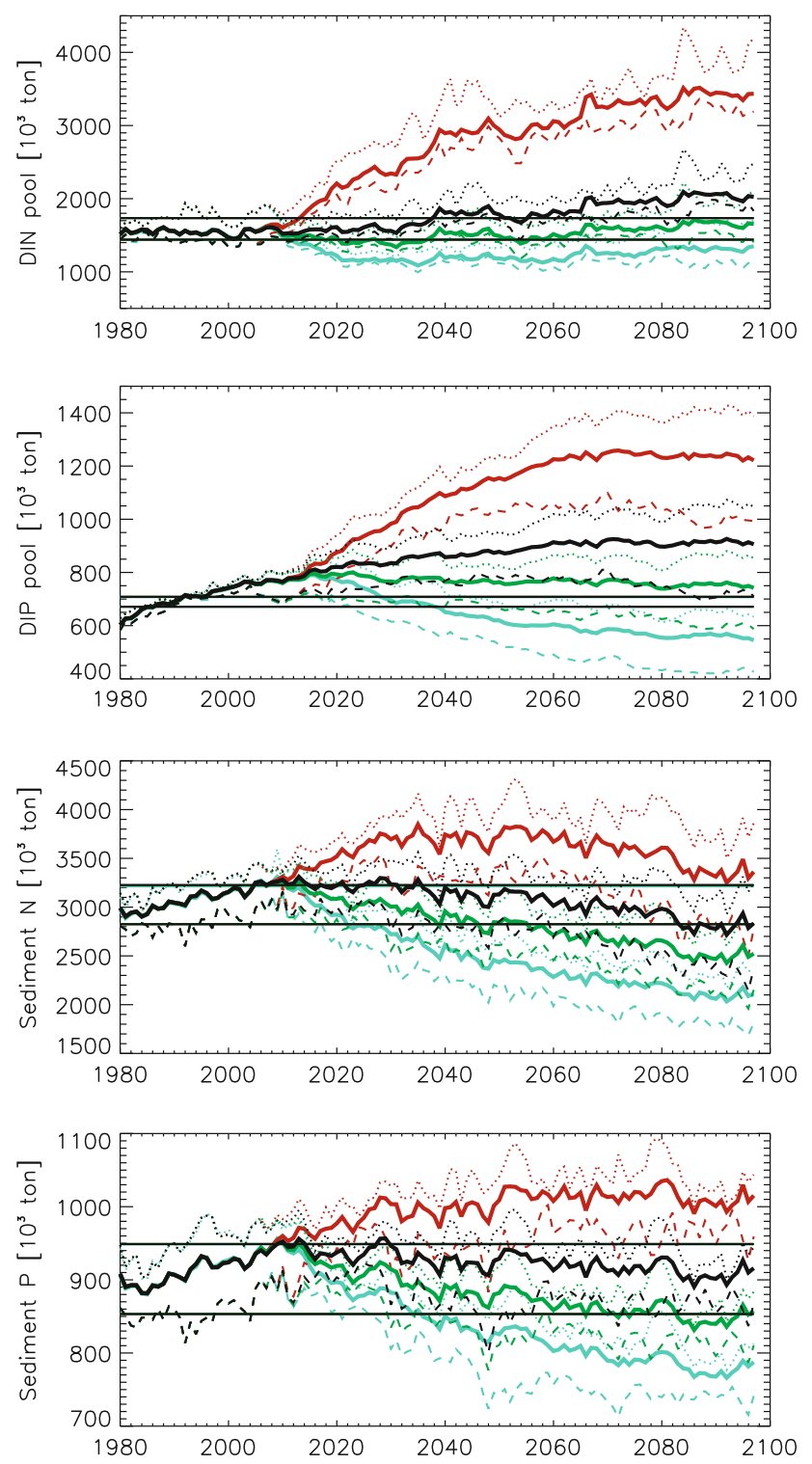

Fig. 9 Ensemble mean volume averaged pools of dissolved inorganic nitrogen (DIN) and phosphorus (DIP) and area averaged pools of nitrogen and phosphorus in the sediments (in kton) for the entire Baltic including Kattegat as a function of time (solid lines): BSAP (blue), CLEG (green), REF (black) and BAU (red). Maximum and minimum values of each ensemble are shown by dotted and dashed lines, respectively. Straight lines indicate the mean maximum and mininum values during 1978-2007

warmer water, in the coastal zone with only weak vertical stratification both the surface and bottom oxygen concentrations decrease slightly. The decrease is larger in regions with larger water depth and with a permanent halocline (Fig. 10). We found the largest decrease of bottom oxygen concentrations in the HADCM3 driven simulation in the central area of the deep Bornholm Basin, Gotland Basin and Bothnian Sea (not shown). In the ensemble mean the bottom oxygen concentration in the Gotland Deep area decreases by more than $1.5 \mathrm{ml} \mathrm{l}^{-1}$ (Fig. 10).
The ensemble spread is largest in regions that are affected by the varying position of the halocline (not shown). Note that the ensemble spread does not differ significantly between the scenarios.

As the phosphorus release capacity of the sediments is oxygen dependent (Eilola et al. 2009), the generally decreased bottom oxygen concentrations cause a decreased storage of phosphorus in the sediments and increased phosphate concentrations in the surface waters (not shown). We found the largest phosphate concentration increase in the HadCM3 driven simulation in the Baltic proper and Gulf of Finland. In the ensemble mean the largest increase of surface phosphate concentrations occurs in the southern Baltic proper (Arkona Basin, Bornholm Basin and southern Gotland Basin) during winter. This signal is a common pattern in all climate projections. The surface phosphate concentration changes in the Gulf of Finland during spring have the largest spread within our ensemble.

In all climate projections the surface nitrate concentration remains unchanged or increases (not shown). The patterns of changing nitrate concentration are similar in all climate projections. Especially during winter and especially in the eastern Gulf of Finland, Gulf of Riga and along the eastern coasts of the Gotland Basin nitrate concentrations increase in future climate. The increased supply of nitrogen from the rivers and the increased oxygen concentrations in the Gulf of Finland (causing decreased denitrification) might be the reasons for the increased nitrate concentrations particularly in the coastal zone close to the river mouths of the large rivers.

Both increased temperatures and increased concentrations of nitrate and phosphate during winter affect the spring and summer blooms (not shown). In particular during spring the concentrations of flagellates and others increase in the eastern Baltic proper, Gulf of Riga and Gulf of Finland. During summer and autumn the concentrations of cyanobacteria increase in the southern Baltic proper in all climate projections. In the Gulf of Finland cyanobacteria blooms are also more intensive in the HadCM3 driven simulation whereas in ECHAM5 driven simulations no significant changes are found. Both flagellate and others and cyanobacteria changes affect phytoplankton concentrations in future climate (Fig. 10).

As a consequence of simulated phytoplankton and detritus changes, Secchi depth in the southern Baltic proper decreases particularly during summer and autumn (Fig. 10). In the ensemble mean the largest Secchi depth changes exceed $1 \mathrm{~m}$.

\subsubsection{Projected changes for BSAP}

As mentioned in the previous section the bottom oxygen concentration decreases significantly in the HadCM3 
BSAP
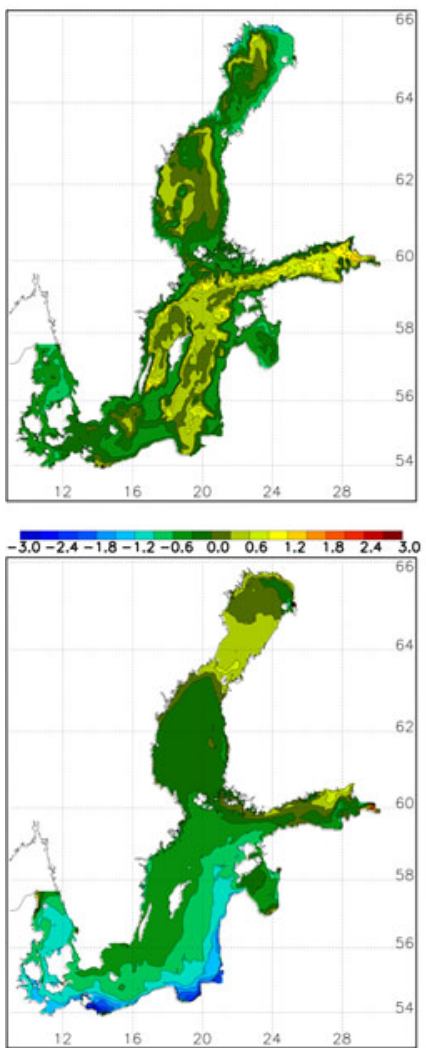

$\begin{array}{lllllll}-2.5-2.0-1.5-1.0-0.5 & 0.0 & 0.5 & 1.0 & 1.5 & 2.0 & 2.5\end{array}$
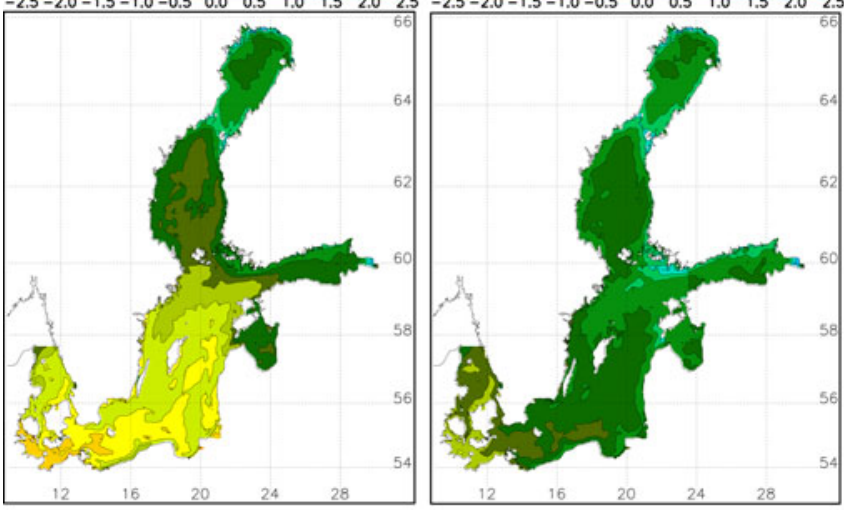

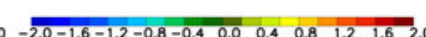

Fig. 10 From top to bottom ensemble mean changes between 2070-2099 and 1978-2007 of summer (June-August) bottom oxygen concentration (in $\mathrm{ml} \mathrm{l}^{-1}$ ), spring (March-May) phytoplankton concentration vertically averaged for the upper $10 \mathrm{~m}$ (in $\mathrm{mgChl} \mathrm{m}^{-3}$ ) and spring Secchi depth (in $\mathrm{m}$ ) are shown. From left to right the results of

driven simulation assuming reference nutrient loads of the REF scenario. Hence, in the BSAP scenario the improvements of the nutrient load reductions will be counteracted by the effect of changing climate at the end of the century. As a consequence, in the HadCM3 driven simulation under the BSAP scenario bottom oxygen concentration changes are only small (not shown). In the ECHAM5 driven simulations
BAU
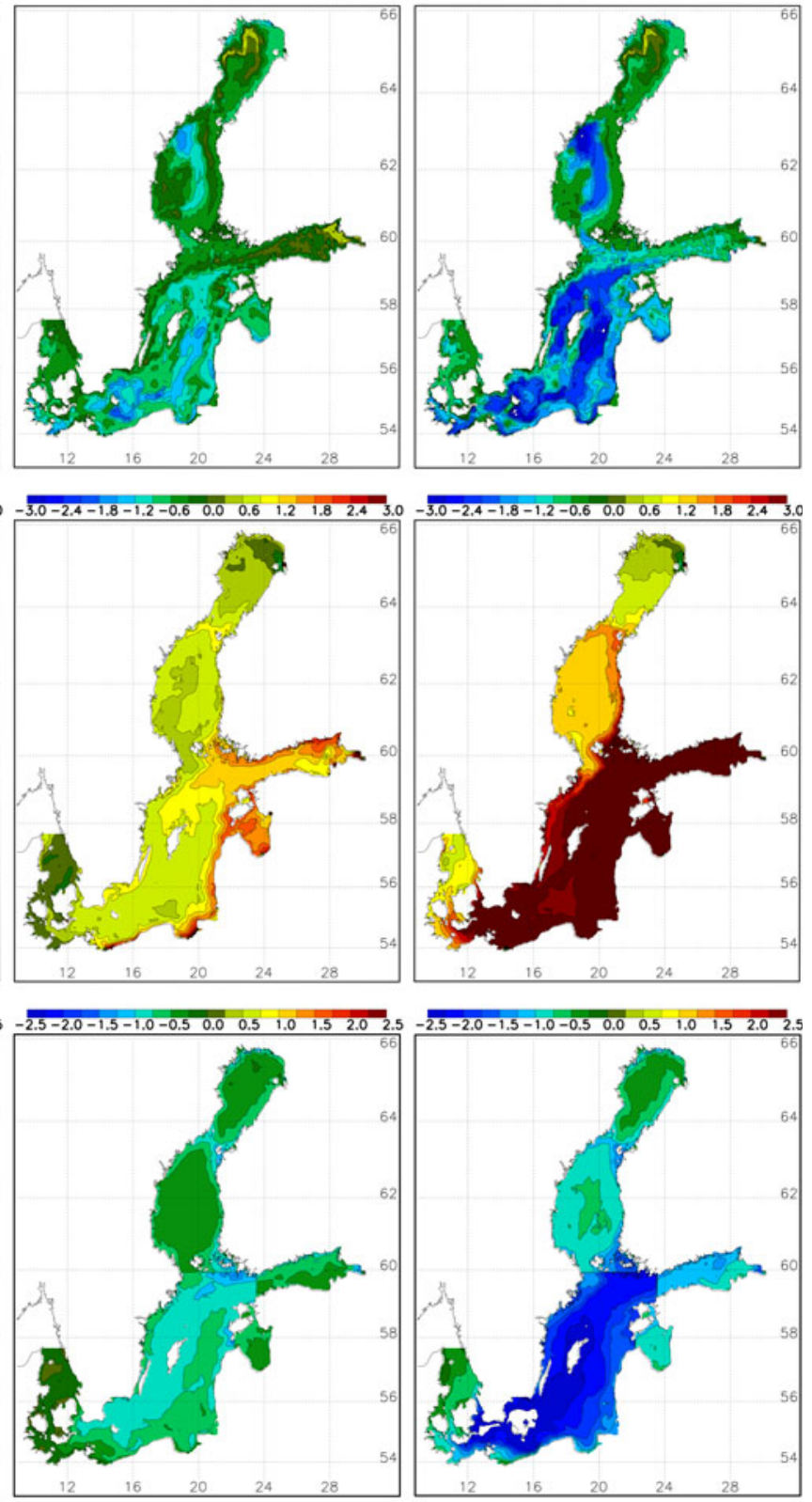

the nutrient load scenarios BSAP, CLEG, REF and BAU are depicted. In BAU phytoplankton concentration increases larger than $2.5 \mathrm{mgChl}$ $\mathrm{m}^{-3}$ and Secchi depth decreases larger than $2 \mathrm{~m}$ are depicted in brown and white, respectively

we found increased bottom oxygen concentrations in the Gulf of Finland and in the Gotland Basin when we applied the BSAP. In the ECHAM5-r1-A1B and A2 driven simulations we found the largest increases of the bottom oxygen concentration along the slopes of the Gotland Basin and in the Gulf of Finland due to the deeping of the halocline and the corresponding decreased stratification in that depth interval. 
While in the HadCM3 driven simulation surface phosphate and nitrate concentration changes are small, we found in ECHAM5 driven simulations in the Gulf of Finland reduced surface phosphate and increased surface nitrate concentrations. Thus, changes of surface nutrient concentrations are largely controlled by changing bottom oxygen concentrations (Savchuk 2010). As shown below water temperature changes affect the decomposition of organic matter in the sediments and contribute to changes of surface nutrient concentrations.

Surface concentration changes of diatoms, flagellates and others and cyanobacteria are diverse (not shown). During spring in all scenario simulations surface diatom concentrations decrease especially along the southern and eastern coasts of the Baltic proper and in the Gulf of Finland. To the contrary, we found slight increases of the surface concentrations of flagellate and others mainly in the Gulf of Finland. Cyanobacteria concentrations increase in the southern Baltic proper (mainly in the Bornholm Basin) in the HadCM3 driven simulation and remain basically unchanged in ECHAM5 driven simulations. During spring surface phytoplankton concentrations in the ECHAM5 driven simulations decrease following diatom concentration changes. During summer we found slight surface phytoplankton concentration increases in the southern Baltic proper in the HadCM3 driven simulation following cyanobacteria concentration changes. Corresponding increases of Secchi depth during spring amount to about 1 $\mathrm{m}$ at maximum. During summer Secchi depth in the HadCM3 driven simulation decreases by about $0.5 \mathrm{~m}$ at maximum.

In the ensemble mean the summer oxygen concentrations in the deeper regions of the Baltic proper increase only slighthly (Fig. 10). However, in the Gulf of Finland the increases are larger exceeding in some regions $0.9 \mathrm{ml} \mathrm{l}^{-1}$. In the Baltic proper the spring phytoplankton concentrations decrease in a narrow zone along the southeastern coasts, especially in Oder and Gdansk bays (Fig. 10). During spring moderate Secchi depth increases of about 0.6-1 $\mathrm{m}$ are found in the southern Baltic Sea (Arkona and Bornholm basins) (Fig. 10).

\subsubsection{Projected changes for CLEG}

In the HadCM3 driven simulation bottom oxygen concentrations decrease at the end of the century in CLEG almost everywhere (not shown). In the ECHAM5 driven scenarios the bottom oxygen concentrations especially in the Gulf of Finland increase. In the two scenarios with increased wind induced mixing in the Baltic proper (ECHAM5-r1-A1B and ECHAM5-r1-A2) the bottom oxygen concentrations along the slopes increase as well because of the deeper halocline. In the ensemble mean we found small decreases of bottom oxygen concentrations in the deeper parts of the Baltic proper and small increases along the slopes and in the Gulf of Finland (Fig. 10).

As a consequence of the bottom oxygen concentration changes surface phosphate concentrations increase in HadCM3 driven scenario simulations. Nitrate concentration changes are largest in the Gulf of Finland and in the Gulf of Riga in ECHAM5-r1-A1B and ECHAM5-r1-A2 driven simulations.

Concentration changes of diatoms, flagellates and others, and cyanobacteria are relatively small. As the projected phytoplankton concentrations in the ensemble mean slightly increases (with larger changes in the northern Baltic proper), Secchi depth decreases (Fig. 10). Largest changes of about $1 \mathrm{~m}$ are found in the Bornholm Basin in the HadCM3 driven scenario simulation during summer. In the ensemble mean the largest changes are found in the Archipelago Sea and in the entrance of the Gulf of Riga but they do not exceed $0.8 \mathrm{~m}$ (except in the river mouth region of the river Neva) (Fig. 10).

\subsubsection{Projected changes for BAU}

In the BAU scenario the impact of increased nutrient loads and the impact of changing climate have large consequences for the marine environment. Large reductions of bottom oxygen concentrations (Fig. 10), large increases of phosphate and nitrate concentrations at the surface of the Baltic proper in particular during winter (not shown) and large increases of both the spring and summer blooms characterize the BAU scenario (Fig. 10). In this scenario Secchi depth in the south-western Baltic at the end of the century is projected to be more than $2 \mathrm{~m}$ smaller compared to present conditions (Fig. 10).

\subsection{Cause-and-effect studies}

The impact of changing climate on the Baltic Sea biogeochemistry in the various nutrient load scenarios is studied further by employing the sensitivity experiments, TAIRCLIM and RUNOFFCLIM (Sect. 2.7). In the following we focus on scenario simulations driven by ECHAM5-r3-A1B combined with the nutrient load scenarios REF and BSAP (Figs. 11, 12).

The increase of the average water temperature in the ECHAM5-r3-A1B driven simulation from about $6.5^{\circ} \mathrm{C}$ during $1969-1998$ to about $8.5{ }^{\circ} \mathrm{C}$ at the end of the century (caused by the increased air temperature over the Baltic Sea, see Table 4) enhances the decomposition of organic matter in the sediments. In the present version of SCOBI the time scale for decomposition will be shortened by a factor of two if the bottom water temperature increases by about $5{ }^{\circ} \mathrm{C}$. However, feedback mechanisms may 

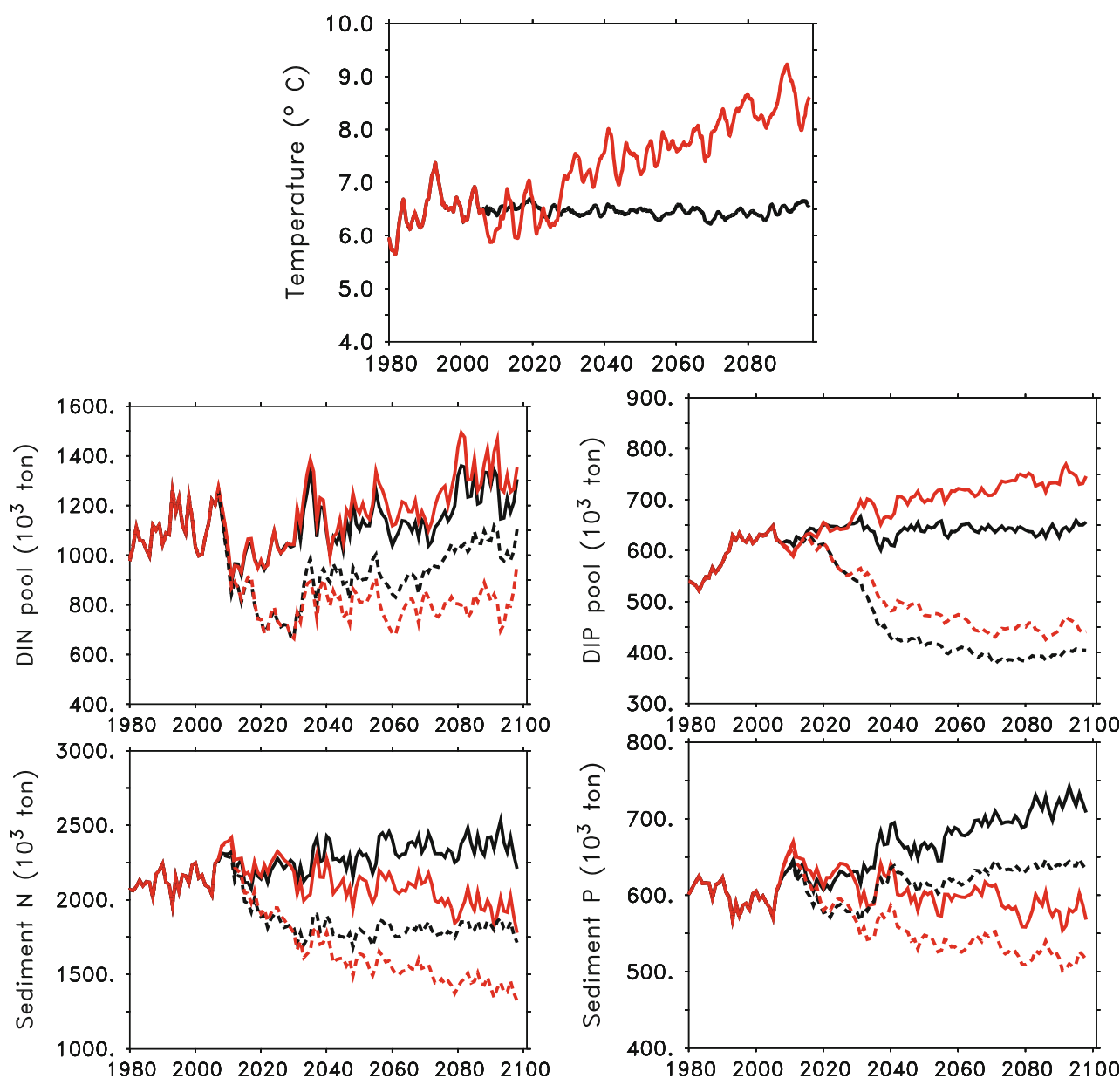

Fig. 11 Volume averaged temperature (in ${ }^{\circ} \mathrm{C}$ ), dissolved inorganic nitrogen (DIN) and phosphorus (DIP) in the water column and area averaged pools of nitrogen and phosphorus in the sediments (in kton) for 1961-2099 in ECHAM5-r3-A1B driven simulations. The various curves show results in the Baltic proper (Arkona Basin, Bornholm

contribute to a further acceleration of the decomposition (see Sect. 4).

Due to the rising water temperature in REF the concentrations of nitrogen and phosphorus in the sediments decrease (Fig. 11) causing increased nutrient concentrations in the surface layer that are available for the production of organic material during the spring bloom (not shown). The effect is larger for phosphorus than for nitrogen because other processes, e.g. denitrification, change as well and modify the nitrogen cycle. This might also be the reason that in the BSAP scenario the pool of DIN in the water column decreases with increasing water temperature instead of an increase as in the REF scenario (Fig. 11).

Increased nutrient concentrations in the surface layer during winter result in increased phytoplankton concentrations during spring and summer and in decreased bottom oxygen concentrations during all seasons due to increased

Basin, Gotland Basin), Gulf of Finland and Gulf of Riga from the nutrient load scenarios REF (solid lines) and BSAP (dashed lines) with (red) and without (TAIRCLIM; black) the projected temperature increase. The volume averaged temperature is filtered using a 1-year running mean of the 2-daily model results

decomposition of organic material in the deep water (Fig. 12). For instance, the bottom oxygen concentrations in the ECHAM5-r3-A1B driven simulation in the REF scenario decrease in the deeper regions of the eastern Gotland Basin by about $0.9-1.2 \mathrm{ml} \mathrm{l}^{-1}$. In the corresponding TAIRCLIM scenario simulation without any changes of the water temperature the bottom oxygen concentrations decrease in the same regions by only $0.3-0.6 \mathrm{ml} \mathrm{l}^{-1}$ (due to the increased nutrient supply, see Fig. 6).

In the BSAP scenario the bottom oxygen concentrations in the deeper parts of the eastern Gotland Basin increase by about $0.3-1.2 \mathrm{ml} \mathrm{l}^{-1}$ and are not affected by the changing water temperatures (compare BSAP and BSAP-TAIRCLIM in Fig. 12). However, in the Gulf of Finland the increase of the bottom oxygen concentrations is about $0.6 \mathrm{ml} \mathrm{l}^{-1}$ larger in TAIRCLIM compared to the scenario simulation with changing water temperature. 


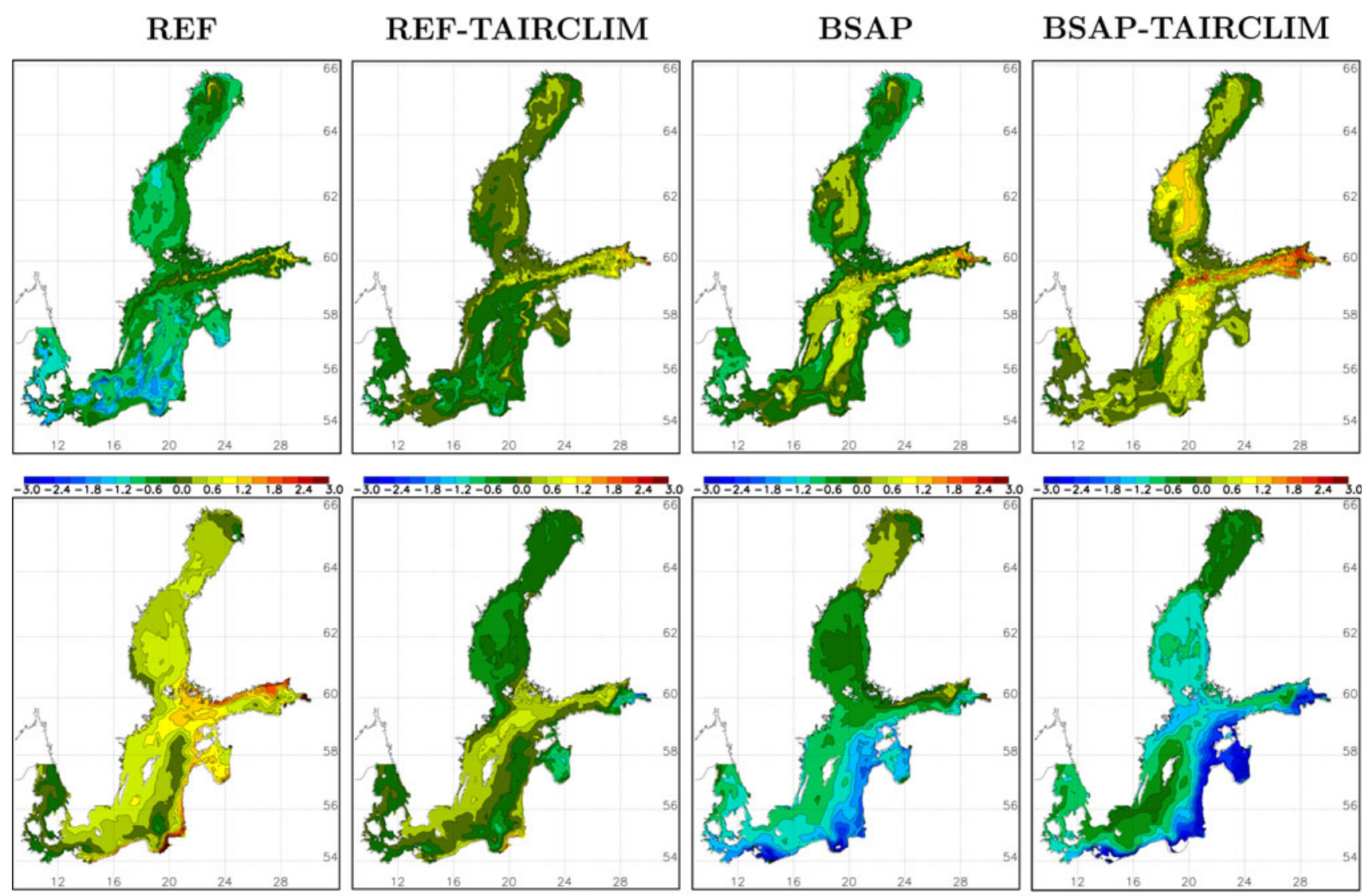

Fig. 12 Changes of summer (June-August) mean bottom oxygen concentration (in $\mathrm{ml}^{-1}$, upper panels) and spring (March-May) mean phytoplankton concentration (in $\mathrm{mg} \mathrm{Chl} \mathrm{m}^{-3}$, lower panels)

In addition to the accelerated decomposition of organic material in the sediments the oxygen saturation concentration decreases in warmer water. However, this effect is smaller than the discussed increase of the oxygen consumption and causes changes of $0.3-0.4 \mathrm{ml}^{-1}$ in maximum.

The results of the sensitivity experiments with climatological mean runoff (RUNOFFCLIM, not shown) confirm that increased phytoplankton and decreased bottom oxygen concentrations are partly also explained by the increased nutrient supply from land (Fig. 6). Note that in our experiments the increased nutrient loads are caused by increased volume flows due to the increased net precipitation over land (Table 5).

\section{Discussion}

Projections of the impact of climate change on the Baltic ecosystem are not forecasts of future conditions for the marine environment, like weather forecasts, but depend on additional assumptions on the future socio-economic development both worldwide and in the Baltic Sea region. between 2070-2099 and 1978-2007 in ECHAM5-r3-A1B driven simulations. From left to right: REF, REF-TAIRCLIM, BSAP, BSAPTAIRCLIM

For instance, future greenhouse gas emissions, nutrient loads from rivers to the sea, nutrient emissions from point sources and atmospheric deposition of nutrients are important drivers of both the regional climate and the marine environment. Hence, scenarios need to be developed that take possible socio-economic changes into account, like changes of the human population, life-style (including food and energy consumption), agricultural practices, etc.

In this study we applied the detailed greenhouse gas emission scenarios developed by the Intergovernmental Panel on Climate Change (IPCC) (Nakićenović et al. 2000). However, consistent socio-economic scenarios on both global and regional scales are not available. Hence, we implemented nutrient load scenarios that follow policy scenarios for the Baltic Sea suggested by HELCOM (2007). These scenarios are not consistent with the global scenarios used for the GCM simulations but are to our knowledge the only available scenarios for the Baltic Sea region. Hence, it is obvious that due to the large range of plausible nutrient load scenarios the uncertainties of our projections are large. 
Other uncertainties of our projections are related to biases of global and regional climate models and have been discussed earlier, e.g. by Christensen and Christensen (2007), Christensen et al. (2007), Kjellström et al. (2011), Nikulin et al. (2011), Räisänen et al. (2004), Meier et al. (2011c).

Especially, projected changes of the surface wind fields are rather uncertain for the Baltic Sea region (Nikulin et al. 2011). As wind speed changes are important drivers of future changes of the vertical stratification in the Baltic Sea, the uncertainties affect projections of the marine ecosystem considerably. For instance, in ECHAM5 driven simulations (e.g. Neumann 2010, this study) the wind speed changes are much smaller than in ECHAM4 driven simulations (e.g. Meier et al. 2011b) causing large differences in bottom oxygen concentration changes and subsequent changes of the nutrient cycles in the Baltic.

Further, the functioning of some key processes of the coupled physical-biogeochemical system are not well known (Eilola et al. 2011). These shortcomings affect the sensitivity of the model response to changing climate and changing nutrient loads (Meier et al. 2011b). For instance, the processes controlling nutrient fluxes between the bottom water and the sediments are poorly understood (e.g. Eilola et al. 2009; Almroth-Rosell et al. 2011).

The results of this study suggest that nutrient loads in future climate may increase due to increased runoff. As the calculated changes are larger than those reported by Meier et al. (2011b) the effects on ecological quality indicators, like bottom oxygen concentration, phytoplankton concentration and Secchi depth (Fig. 10) are larger than in the scenario simulations by Meier et al. (2011b). Neumann (2010) calculated nutrient load changes with the same approach as in our study following Stålnacke et al. (1999). He found similar large increases of the freshwater budget of about $20 \%$ in his two scenario simulations (A1B and B1) than in our experiments. However, in his simulations the oxygen concentration of the deep water improves slightly causing a reduction of future hypoxic areas. In contrast, we found decreasing bottom oxygen concentrations in all scenarios with increasing nutrient loads. Thus, the sensitivity of different models to changing nutrient loads seems to differ significantly.

In the scenario simulations of this study another process is important which may affect the marine ecosystem significantly. Increased water temperatures cause not only reduced oxygen saturation concentrations, but also (and perhaps even more important) an increased decomposition of organic matter in the sediments. The presented results suggest that in future climate less nutrients will be stored in the sediments due to the increased remineralization under higher temperatures (Fig. 11).

In SCOBI the parameters describing the nutrient fluxes from the sediments were chosen such that the time scale for decomposition will be shortened by a factor of two if the bottom water temperature increases by about $5^{\circ} \mathrm{C}$. Very likely the time scale is even shorter because of a feedback mechanism due to changing bottom oxygen concentrations. Increased remineralization of phosphorus will increase the phytoplankton production which will increase the oxygen consumption which in turn will result in lower bottom oxygen concentrations. Thus, the phosphorus retention capacity will be lower causing lower/higher concentrations of phosphorus in the sediments/water column (Eilola et al. 2009). For nitrogen the processes are even more complex because increased decomposition will also affect denitrification.

In this study the parameterization of the temperature dependent remineralization of the Ecological Regional Ocean Model (ERGOM) (Neumann et al. 2002; Neumann and Schernewski 2008) was used. Thus, the sensitivity to temperature changes is about 30 times larger than in the scenario simulations by Meier et al. (2011b) which explains the larger impact of increased decomposition on the results of our scenario simulations. As the true remineralization rate and its temperature dependency are unknown, the role of changing remineralization in future climate remains uncertain.

\section{Summary and conclusions}

In this study we focussed on annual and seasonal mean changes of ecological quality indicators like bottom oxygen concentration, phytoplankton concentration and Secchi depth describing the environmental status of the Baltic Sea. Agreement and disagreement of the simulated changes were assessed from the statistics of an ensemble of 16 scenario simulations. Projected changes at the end of the twenty first century are usually larger than biases induced by the deficiencies of GCMs at the regional scale. Especially ensemble mean biases are smaller than ensemble mean changes stressing the added value of ensemble modelling.

In agreement with earlier studies (Meier 2006; Meier et al. 2006, 2011b; Neumann 2010) we found that at the end of the twenty first century water temperature will increase, runoff will increase, and salinity will decrease. However, in contrast to earlier ECHAM4 driven simulations (Meier et al. 2011b) our results do not indicate considerable wind speed and gustiness changes over the Baltic proper. Hence, stratification changes due to wind induced mixing changes are relatively small.

In correspondence with earlier studies we found that the impact of changing climate on the Baltic biogeochemistry might be significant. The model simulations suggest that in addition to eutrophication changing climate is an important 
stressor for the Baltic ecosystem. With the help of sensitivity experiments we identified two processes that in our model are mainly responsible for environmental changes due to changing climate. Due to increased temperature and increased net precipitation in the Baltic catchment area the decomposition of organic material in the sediments will be accelerated and the nutrient loads from land will increase. Both processes cause increased nutrient concentrations in the surface layer and consequently an acceleration of eutrophication in the Baltic Sea.

According to our scenario simulations with reference loads water quality (measured by bottom oxygen concentrations, phytoplankton concentrations and Secchi depths) will be deteriorated in future climate. For instance, in summer the ensemble mean of the Secchi depth will decrease in the southern Baltic proper by up to $1.5 \mathrm{~m}$.

According to our results nutrient load reductions performed under current legislation will not be sufficient to improve the water quality at the end of the century. The climate effect is larger than the impact of nutrient load reductions and Secchi depth will decrease especially in the southern Baltic proper. The larger nutrient load reductions of the BSAP will improve the water quality at the end of the century. However for the same targets larger reductions will be necessary compared to present climate. In summer the ensemble mean of the Secchi depth will increase in the southern Baltic proper by about $1 \mathrm{~m}$ in maximum. In case of an exponential growth of agriculture following a pessimistic business-as-usual scenario bottom oxygen concentrations will decrease, surface nutrient concentrations will increase and Secchi depth will decrease significantly. During the warmer seasons (spring to autumn) the ensemble mean of the Secchi depth in the southern Baltic proper will decrease by more than $2 \mathrm{~m}$ in some regions.

Acknowledgments The research presented in this study is part of the project ECOSUPPORT (Advanced modelling tool for scenarios of the Baltic Sea ECOsystem to SUPPORT decision making) and has received funding from the European Community's Seventh Framework Programme (FP/2007-2013) under grant agreement no. 217246 made with BONUS, the joint Baltic Sea research and development programme, and from the Swedish Environmental Protection Agency (SEPA, ref. no. 08/381). The RCO-SCOBI model simulations were partly performed on the climate computing resources 'Ekman' and 'Vagn' that are operated by the National Supercomputer Centre (NSC) at Linköping University and the Centre for High Performance Computing (PDC) at the Royal Institute of Technology in Stockholm, respectively. These computing resources are funded by a grant from the Knut and Alice Wallenberg Foundation. We thank our colleagues Zohreh Ranjbar and Ivan Kuznetsov for the help with the preparation of figures and three anonymous reviewers for their comments that helped to improve the manuscript.

Open Access This article is distributed under the terms of the Creative Commons Attribution License which permits any use, distribution, and reproduction in any medium, provided the original author(s) and the source are credited.

\section{References}

Almroth-Rosell E, Eilola K, Hordoir R, Meier HEM, Hall POJ (2011) Transport of fresh and resuspended particulate organic material in the Baltic Sea-a model study. J Mar Syst. doi:10.1016/j. jmarsys.2011.02.005

BACC author team (2008) Assessment of climate change for the Baltic Sea basin. Regional climate studies. Springer, Berlin

Bergström S, Carlsson B (1994) River runoff to the Baltic Sea: 1950-1990. Ambio 23:280-287

Brasseur O (2001) Development and application of a physical approach to estimating wind gusts. Mon Weather Rev 129(1):5-25

Christensen JH, Christensen OB (2007) A summary of the PRUDENCE model projections of changes in European climate by the end of the century. Clim Change 81(suppl 1):7-30

Christensen JH, Hewitson B, Busuioc A, Chen A, Gao X, co authors (2007) Regional climate projections. In: Solomon S, Qin D, Manning M, Chen Z, Marquis M, co editors (eds) Climate change 2007: the physical science basis. Contribution of working group 1 to the fourth assessment report of the Intergovernmental Panel on Climate Change, Cambridge University Press, Cambridge, pp 847-940

Döscher R, Willén U, Jones C, Rutgersson A, Meier HEM, Hansson U, Graham LP (2002) The development of the regional coupled ocean-atmosphere model RCAO. Boreal Environ Res 7:183-192

Eilola K, Meier HEM, Almroth E (2009) On the dynamics of oxygen, phosphorus and cyanobacteria in the Baltic Sea; a model study. J Mar Syst 75:163-184

Eilola K, Gustafsson BG, Kuznetsov I, Meier HEM, Neumann T, Savchuk OP (2011) Evaluation of biogeochemical cycles in an ensemble of three state-of-the-art numerical models of the Baltic Sea. J Mar Syst 88:267-284

Gerdes R, Köberle C, Willebrand J (1991) The influence of numerical advection schemes on the results of ocean general circulation models. Clim Dyn 5:211-226

Gordon C, Cooper C, Senior CA, Banks H, Gregory JM, Johns TC, Mitchell JFB, Wood RA (2000) The simulation of SST, sea ice extent and ocean heat transports in a version of the Hadley Centre coupled model without flux adjustments. Clim Dyn 16:147-166

Graham LP, Hagemann S, Jaun S, Beniston M (2007) On interpreting hydrological change from regional climate models. Clim Change 81(suppl 1):97-122

Graham PL (2004) Climate change effects on river flow to the Baltic Sea. Ambio 33:235-241

Gustafsson BG, Andersson HC (2001) Modeling the exchange of the Baltic Sea from the meridional atmospheric pressure difference across the North Sea. J Geophys Res 106:19,731-19,744

Gustafsson BG, Savchuk OP, Meier HEM (2011) Load scenarios for ECOSUPPORT. Technical report 4, Baltic Nest Institute, Stockholm, Sweden, ISSN 978-91-86655-03-7

HELCOM (2007) Toward a Baltic Sea unaffected by eutrophication. Background document to Helcom Ministerial Meeting, Krakow, Poland. Tech. rep., Helsinki Commission, Helsinki, Finland

Höglund A, Meier HEM, Broman B, Kriezi E (2009) Validation and correction of regionalised ERA-40 wind fields over the Baltic Sea using the Rossby Centre Atmosphere model RCA3.0. Tech. Rep. No. 97, Rapport Oceanografi, 29 pp

Hordoir R, Meier HEM (2011) Effect of climate change on the thermal stratification of the Baltic Sea-a sensitivity experiment. Clim Dyn. doi:10.1007/s00382-011-1036-y, (published on-line 4 March 2011)

Humborg C, Mörth C, Sundbom M, Wulff F (2007) Riverine transport of biogenic elements to the Baltic Sea-past and possible future perspectives. Hydrol Earth Syst Sci 11(5):1593-1607 
Hunke EC, Dukowicz JK (1997) An elastic-viscous-plastic model for sea ice dynamics. J Phys Oceanogr 27:1849-1867

Jungclaus JH, Botzet M, Haak H, Keenlyside N, Luo JJ, co authors (2006) Ocean circulation and tropical variability in the coupled ECHAM5/MPI-OM. J Clim 19:3952-3972

Killworth P, Stainforth D, Webb D, Paterson S (1991) The development of a free-surface Bryan-Cox-Semtner ocean model. J Phys Oceanogr 21:1333-1348

Kjellström E, Lind P (2009) Changes in the water budget in the Baltic Sea drainage basin in future climates as simulated by the regional climate model RCA3. Boreal Environ Res 14(1):114-124

Kjellström E, Nikulin G, Hansson U, Strandberg G, Ullerstig A (2011) 21st century changes in the European climate: uncertainties derived from an ensemble of regional climate model simulations. Tellus 63A:24-40

Kratzer S, Håkansson B, Sahlin C (2003) Assessing Secchi and photic zone depth in the Baltic Sea from satellite data. Ambio 32(8):577-585

Lind P, Kjellström E (2009) Water budget in the Baltic Sea drainage basin: evolution of simulated fluxes in a regional climate model. Boreal Environ Res 14(1):56-67

Marmefelt E, Arheimer B, Langner J (1999) An integrated biogeochemical model system for the Baltic Sea. Hydrobiologia 393:45-56

Meier HEM (2001) On the parameterization of mixing in threedimensional Baltic Sea models. J Geophys Res 106:30,997-31,016

Meier HEM (2006) Baltic Sea climate in the late twenty-first century: a dynamical downscaling approach using two global models and two emission scenarios. Clim Dyn 27:39-68

Meier HEM (2007) Modeling the pathways and ages of inflowing salt- and freshwater in the Baltic Sea. Estuar Coast Shelf Sci 74(4):717-734

Meier HEM, Kauker F (2003) Modeling decadal variability of the Baltic Sea: 2. Role of freshwater inflow and large-scale atmospheric circulation for salinity. J Geophys Res 108(C11): 3368. doi:10.1029/2003JC001,799

Meier HEM, Döscher R, Faxén T (2003) A multiprocessor coupled ice-ocean model for the Baltic Sea: application to salt inflow. J Geophys Res 108(C8):3273. doi:10.1029/2000JC000,521

Meier HEM, Kjellström E, Graham LP (2006) Estimating uncertainties of projected Baltic Sea salinity in the late 21st century. Geophys Res Lett 33(15):L15,705

Meier H, Andersson H, Dieterich C, Eilola K, Gustafsson BG, Höglund A, Hordoir R, Schimanke S (2011a) Transient scenario simulations for the Baltic Sea Region during the $21^{\text {st }}$ century. Rapport Oceanografi 108, Swedish Meteorological and Hydrological Institute, SE-60176 Norrköping, Sweden

Meier HEM, Eilola K, Almroth E (2011b) Climate-related changes in marine ecosystems simulated with a three-dimensional coupled biogeochemical-physical model of the Baltic Sea. Clim Res 48:31-55

Meier HEM, Höglund A, Döscher R, Andersson H, Löptien U, Kjellström E (2011c) Quality assessment of atmospheric surface fields over the Baltic Sea of an ensemble of regional climate model simulations with respect to ocean dynamics. Oceanologia 53(1-TI):193-227
Monin AS, Obukhov AM (1954) Basic laws of turbulent mixing in the surface layer of the atmosphere. Tr Akad Nauk SSSR Geofiz Inst 24:163-187

Nakićenović N, Alcamo J, Davis G, de Vries B et al (2000) Emission scenarios. A special report of working group III of the Intergovernmental Panel on Climate Change. Cambridge University Press, Cambridge

Neumann T (2010) Climate-change effects on the Baltic Sea ecosystem: a model study. J Mar Syst 81:213-224

Neumann T, Schernewski G (2008) Eutrophication in the Baltic Sea and shifts in nitrogen fixation analyzed with a 3D ecosystem model. J Mar Syst 74:592-602

Neumann T, Fennel W, Kremp C (2002) Experimental simulations with an ecosystem model of the Baltic Sea: a nutrient load reduction experiment. Global Biogeochem Cycle 16(3):1033

Nikulin G, Kjellström E, Hansson U, Strandberg G, Ullerstig A (2011) Evaluation and future projections of temperature, precipitation and wind extremes over Europe in an ensemble of regional climate simulations. Tellus 63A:41-55

Räisänen J, Hansson U, Ullerstig A, Döscher R, Graham LP, Jones C, Meier HEM, Samuelsson P, Willén U (2004) European climate in the late twenty-first century: regional simulations with two driving global models and two forcing scenarios. Clim Dyn 22:13-31

Rodi W (1980) Turbulence models and their application in hydraulics - a state-of-the-art review. International Association for Hydraulogy Research, Delft, The Netherlands, 104 pp

Roeckner E, Bengtsson L, Feichter J, Lelieveld J, Rodhe H (1999) Transient climate change simulations with a coupled atmosphere-ocean GCM including the tropospheric sulfur cycle. J Clim 12:3004-3032

Roeckner E, Brokopf R, Esch M, Giorgetta M, Hagemann S, co authors (2006) Sensitivity of simulated climate to horizontal and vertical resolution in the ECHAM5 atmosphere model. J Clim 19:3771-3791

Samuelsson P, Jones CG, Willén U, Ullerstig A, Golvik S, Hansson U, Jansson C, Kjellström E, Nikulin G, Wyser K (2011) The Rossby Centre regional climate model RCA3: model description and performance. Tellus 63A:4-23

Savchuk O (2010) Large-scale dynamics of hypoxia in the Baltic Sea. In: Chemical structure of pelagic redox interfaces: observation and modelling, Hdb. Env. Chem. Springer, Berlin

Stålnacke P, Grimvall A, Sundblad K, Tonderski A (1999) Estimation of riverine loads of nitrogen and phosphorus to the Baltic Sea 1970-1993. Environ Monit Assess 58:173-200

Uppala SM, Kållberg PW, Simmons AJ, Andrae U, DaCosta Bechtold V, co authors (1989) The ERA-40 re-analysis. Q J Roy Meteor Soc 131((612):2961-3012

Wang J, Ikeda M, Zhang S, Gerdes R (2005) Linking the northern hemisphere sea ice reduction trend and the quasi-decadal Arctic Sea Ice oscillation. Clim Dyn 24:115-130

Webb DJ, Coward AC, de Cuevas BA, Gwilliam CS (1997) A multiprocessor ocean circulation model using message passing. J Atmos Oceanic Technol 14:175-183

Wulff F, Savchuk OP, Sokolov A, Humborg C (2007) Management options and effects on a marine ecosystem: assessing the future of the Baltic. AMBIO 36:243-249 